\title{
Hypoxia induces a transcriptional early primitive streak signature in pluripotent cells enhancing spontaneous elongation and lineage representation in gastruloids
} \author{
Aydan Bulut-Karslioglu1,11, §

\footnotetext{
${ }^{1}$ Max Planck Institute for Molecular Genetics, Berlin, Germany

2 Charite Molecular Medicine, Berlin, Germany

${ }_{3}$ Max Planck Institute of Molecular Cell Biology and Genetics, Dresden, Germany

${ }^{4}$ Medical School of the Democritus University of Thrace, Greece

5 Bilkent University, Ankara, Turkey

6 Istanbul Technical University, Istanbul, Turkey

7 Max Planck Institute for Molecular Biomedicine, Münster, Germany

8 Department of Molecular and Cellular Biology, Harvard University, Cambridge, MA, USA

9 Department of Stem Cell and Regenerative Biology, Harvard University, Cambridge, MA, USA

${ }^{10}$ Broad Institute of MIT and Harvard, Cambridge, MA, USA

11 Lead contact

§ Correspondence: Aydan Bulut-Karslioglu Aydan.karslioglu@molgen.mpg.de
}

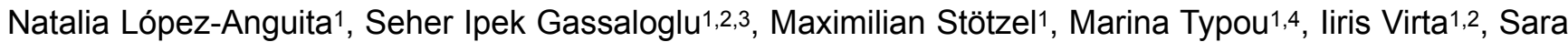
Hetzel $^{1}$, René Buschow ${ }^{1}$, Burak Koksal ${ }^{5}$, Derya Atilla ${ }^{6}$, Ronald Maitschke-Rajasekharan ${ }^{1}$, Rui Chen? Alexandra L. Mattei ${ }^{1,8,9}$, Ivan Bedzhov ${ }^{7}$, David Meierhofer ${ }^{1}$, Alexander Meissner ${ }^{1,9,10}$, Jesse V. Veenvliet ${ }^{1,3}$,

\section{ABSTRACT}

The cellular microenvironment together with intrinsic regulators shapes stem cell identity and differentiation capacity. Mammalian early embryos are exposed to hypoxia in vivo and appear to benefit from hypoxic culture in vitro. Yet, components of the hypoxia response and how their interplay impacts stem cell transcriptional networks and lineage choices remain poorly understood. Here we investigated the molecular effects of acute and prolonged hypoxia on distinct embryonic and extraembryonic stem cell types as well as the functional impact on differentiation potential. We find a temporal and cell type-specific transcriptional response including an early primitive streak signature in hypoxic embryonic stem (ES) cells. Using a 3D gastruloid differentiation model, we show that hypoxiainduced $\mathrm{T}$ expression enables symmetry breaking and axial elongation in the absence of exogenous WNT activation. Importantly, hypoxia also modulates $T$ levels in conventional gastruloids and enhances representation of endodermal and neural markers. Mechanistically, we identify Hif1 $\alpha$ as a central factor that mediates the transcriptional response to hypoxia in balance with epigenetic and metabolic rewiring. Our findings directly link the microenvironment to stem cell function and provide a rationale supportive of applying physiological conditions in models of embryo development

\section{INTRODUCTION}

In most early mammalian embryos, the first three cell types are established and maintained in oxygen tension ranging from 1.5 to $8 \%$ (Fischer and Bavister, 1993; Ottosen et al., 2006; Yedwab et al., 1976). These comprise the pluripotent epiblast, the primitive endoderm (PrE, also known as hypoblast), and the trophectoderm (TE). Upon differentiation, the extraembryonic PrE and TE give rise to the yolk sac and placenta, respectively (Rossant et al., 2003). Local oxygen levels in the embryo are likely subatmospheric until proper placentation at midgestation (Woods et al., 2018). Hypoxia is also endemic to adult stem cell niches (Mohyeldin et al., 2010) and solid tumors (Muz et al., 2015; Rankin and Giaccia, 2016) and as such is a common physiological component of the cellular microenvironment.

In vitro culture of pre-implantation mouse (Meuter et al., 2014; Nguyen et al., 2020), human (Dumoulin et al., 1999; Meintjes et al., 2009; Montfoort et al., 2020) and other mammalian embryos (Batt et al., 1991; Harvey et al., 2004) in hypoxia often improve embryo development or quality by e.g. increasing the inner cell mass size and reducing oxidative DNA damage (Houghton, 2021). Numerous studies on mouse and human ES cells revealed a beneficial effect on ES cell differentiation, especially towards endodermal lineages (Burr et al., 2017; Forristal et al., 
2010; Houghton, 2021; Kusuma et al., 2014; Pimton et al., 2015). Hypoxia is also implemented in some protocols that model mammalian embryo development in a dish (Sozen et al., 2021), yet the mechanisms through which hypoxia exerts its beneficial effects are not clear. The severity and duration of hypoxia are major determinants of the hypoxic response, which is primarily executed by hypoxia-inducible factors (HIF). The canonical hypoxic response entails activation of glycolysis and angiogenesis genes by HIF $1 \alpha$ (Muz et al., 2015; Podkalicka et al., 2020). In addition, hypoxia contributes to epithelialmesenchymal transition (EMT) and invasiveness in various cancers (Muz et al., 2015; Rankin and Giaccia, 2016). EMT is also a cornerstone of embryonic development, as it enables cell movement and migration. In the mouse embryo, radial symmetry breaking happens at the time of gastrulation via formation of the primitive streak (Bardot and Hadjantonakis, 2020). The interplay between signaling pathways including WNT, BMP, and FGF and downstream activities of master transcription factors (TFs) such as Eomes, T (Brachyury), and Snail1 induce EMT and/or define mesodermal and endodermal cells on the posterior side of the embryo (Bardot and Hadjantonakis, 2020). Antagonization of these signals then defines the ectoderm on the anterior side (Bardot and Hadjantonakis, 2020).

Although WNT is not required for mouse preimplantation development (Fan et al., 2020), distinct WNT activities mediate longterm maintenance (Berge et al., 2011; Fan et al., 2020) and resolution of pluripotency (Bardot and Hadjantonakis, 2020) in vivo. In vitro, distinct pluripotent states can be captured (Kinoshita et al., 2021; Neagu et al., 2020; Ying et al., 2008) and differentiation programs can be mimicked (Brink et al., 2014; Hayashi et al., 2011) by modulating the activity of developmental signaling pathways including the WNT pathway. Exogenous WNT activation during differentiation of ES cells aggregates of a defined size leads to $T$ expression and axial elongation, thus generating embryonic organoids resembling the post-implantation embryo (gastruloids) (Beccari et al., 2018; Berge et al., 2008; Brink et al., 2014; Turner et al., 2017; Vianello and Lutolf, 2020). Prolific WNT activity is however undesirable as it hinders the emergence of certain tissues including the neural lineages and reduces structural complexity (Girgin et al., 2021; Olmsted and Paluh, 2021). In vivo, transient, and fine-tuned gene activity underlies tissue diversification in the gastrulating embryo (Mittnenzweig et al., 2021). Moderation of pathway activity is thus crucial to achieve in vivo-like complexity in models of embryo development.

Here we investigated the molecular effects of acute and prolonged hypoxia on transcriptional networks and stem cell identities of embryonic and extraembryonic stem cells. We show that hypoxic ES cells are transcriptionally primed with a primitive streak signature including Wnt3 and $T$ induction. This enables symmetry breaking in gastruloids without exogenous WNT activation. In conventional gastruloids, hypoxia enhances lineage representation in the presence of exogenous WNT activation. This transcriptional response is centrally regulated by Hif1 $\alpha$ and also integrates metabolic and epigenetic responses.

\section{RESULTS}

Exposure of stem cells to hypoxia leads to cell-type-specific transcriptional responses To investigate the impact of hypoxia on transcriptional programs of mouse early embryonic and extraembryonic stem cells, we used ES cells (Evans and Kaufman, 1981; Martin, 1981), extraembryonic endoderm stem (XEN) cells (Kunath et al., 2005) and trophoblast stem (TS) cells (Tanaka et al., 1998), which are in vitro models of the epiblast, PrE, and TE. The acute response to hypoxia in the form of HIF activation and metabolic adjustments occurs within minutes to hours (Pagé et al., 2002). However, the embryo might be exposed to hypoxia for about 9-10 days in vivo between fertilization and $\sim E 9-10$ where proper placentation begins (Woods et al., 2018). Early embryonic and extraembryonic cells are thus likely exposed to hypoxia for at least a few days. To examine the effect of hypoxia on stem cell identity and function in a time-resolved manner, we cultured ES, TS, and XEN cells in hypoxia ( $2 \%$ $\left.\mathrm{O}_{2}\right)$ or normoxia $\left(20 \% \mathrm{O}_{2}\right)$ for up to 7 days and first assessed stem cell marker expression, proliferation, and apoptosis rates (Figure 1A). In general, prolonged culture in hypoxia does 
bioRxiv preprint doi: https://doi.org/10.1101/2021.07.21.452906; this version posted July 22, 2021. The copyright holder for this preprint (which was not certified by peer review) is the author/funder. All rights reserved. No reuse allowed without permission.

A

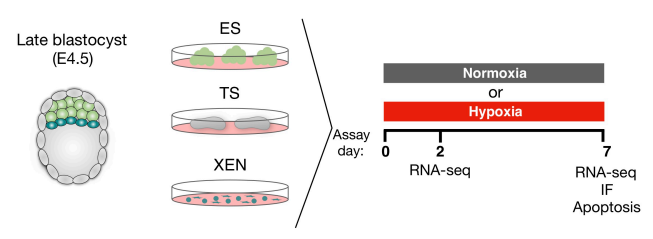

B
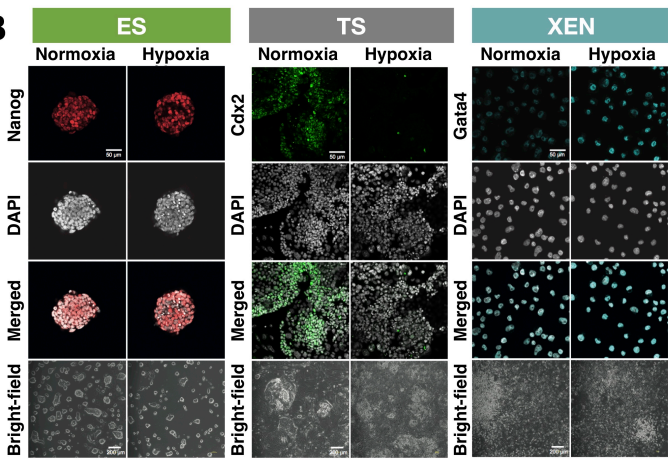

$\mathbf{C}$

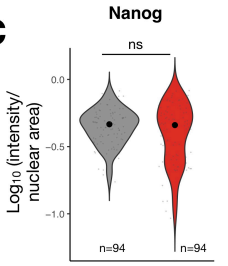

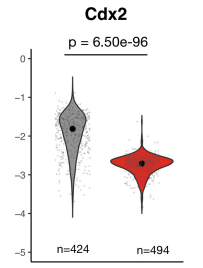

$\square$ Normoxia $\square$ Hypoxia D7

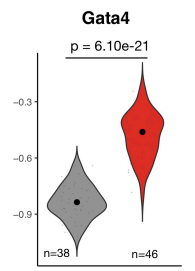

D

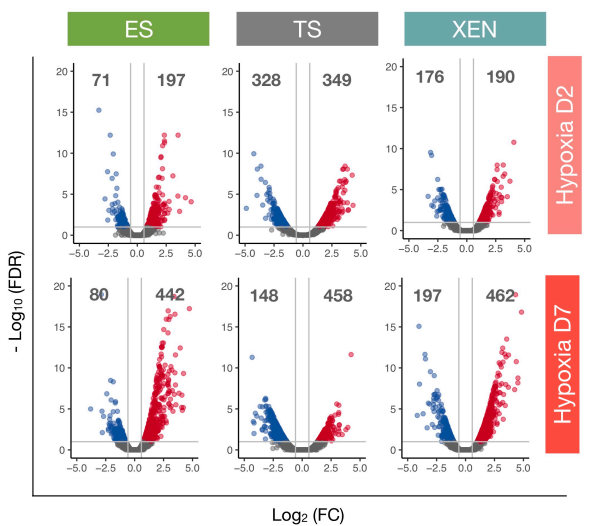

E

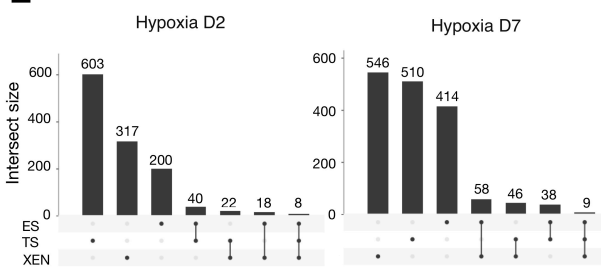

G

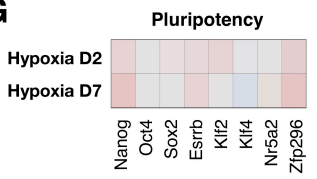

Ectoderm

Hypoxia D2
Hypoxia D7
Endoderm

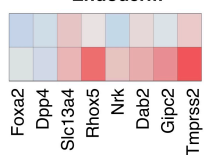

Mesoderm

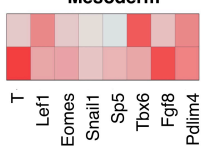

$\log _{2}$ FC TPM
$\mathbf{F}$

GO-BP terms of DEGs in hypoxic ES

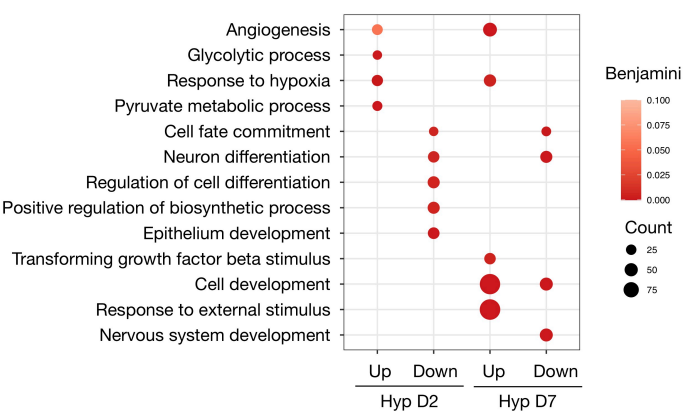

Figure 1. Hypoxia elicits cell type-specific transcriptional responses in ES, TS, and XEN cells.

A) Experimental setup including a schematic of in vivo counterparts of the used stem cell types.

B) Immunofluorescent (IF) staining of stem cell markers and bright-field images of ES, TS, and XEN cells cultured in normoxia or hypoxia for 7 days. Scale bars, 50 and $200 \mu \mathrm{m}$, respectively.

C) Quantification of IF images including those displayed in (B). The fluorescent intensity of each nucleus was measured quantified and normalized to the nuclear area. Each dot represents a cell. $\mathrm{N}$ represents the number of cells quantified per sample. Statistical tests performed are unpaired two-sample Wilcoxon tests.

D) Volcano plots depicting expression fold changes and significance on hypoxia day 2 and day 7 relative to normoxia (|FC|>1.5 and FDR >= 0.1 indicated by the gray lines). Red and blue indicate up- and down-regulated genes. Number of differentially expressed (DE) genes are indicated above each section. Two biological replicates were performed. See Table S1 for the full lists of DE genes.

E) Overlap of DE genes across cell types on hypoxia day 2 and day 7 .

F) Gene ontology-Biological process (GO-BP) terms associated with DE genes in ES cells exposed to acute (d2) or prolonged (d7) hypoxia. Representative significant terms are shown (Benjamini-Hochberg adjusted p-value < 0.1). See Table S2 for full list of GO terms. GO terms associated with DE genes in TS and XEN cells can be found in Figure S1F-G and Table S2.

G) Heatmaps showing expression levels of the indicated pluripotency and lineage-specific genes in hypoxic relative to normoxic ES cells. Germ layer markers were retrieved by analyzing RNAseq data of gastrulating mouse embryos published in (Grosswendt et al., 2020) as explained in See also Figure S1. 
not lead to increased cell death or morphological changes (Figure S1A, 1B). ES and TS cells proliferate slower in hypoxia (ES $p=0.01$, TS non-significant), with a slight increase of $E S$ cells in the $G_{0} / G_{1}$ phase of the cell cycle (Figure S1B, S1C). XEN cell proliferation is largely not affected (Figure S1B). Importantly, ES cells remain undifferentiated and retain the pluripotency marker Nanog after 7 days of hypoxia exposure (Figure 1B, C). In contrast, hypoxia more drastically affects expression of stem cell markers in TS and XEN cells. Hypoxic TS cells downregulate $\mathrm{Cdx} 2$ expression and Gata4 expression is significantly increased in hypoxic XEN cells (Figure 1B, C). Thus, the response to hypoxia appears to be cell type-specific and may impact stem cell function in a tissuespecific manner.

To probe the extent and specificity of the transcriptional response to hypoxia, we next profiled gene expression in each stem cell type on day 2 (acute) or day 7 (prolonged) of hypoxia exposure by bulk RNA sequencing (RNA-seq). Hierarchical clustering based on transcriptome profiles revealed primarily cell type-mediated clusters, indicating that hypoxia in general does not perturb cell identities (Figure S1D, S1E). In line with this observation, a moderate number of genes is significantly differentially expressed (DE) in each cell type and time point ( $|F C|>1.5$, qvalue $<=0.1$, ES: 268 and 522 genes, TS: 677 and 606 genes, XEN: 366 and 659 genes on day 2 and day 7 , respectively) (Figure 1D, Table S1). DE genes are largely cell-typespecific with minimal overlap (Figure 1E). Gene ontology analysis for biological processes of $\mathrm{DE}$ genes shows that the early response to hypoxia entails upregulation of glycolysis and angiogenesis genes in ES cells, but not TS and XEN cells (Figure 1F, Table S2), suggesting that the latter may be metabolically less dependent on oxygen (Figure S1F, S1G, Table S2). In all cell types, genes associated with cell development and differentiation are more deregulated on day 7 , indicating temporally distinct effects of acute and prolonged hypoxia on transcription of specific gene subsets (Figure 1F, S1F, S1G). In ES cells, early mesoderm-instructive genes (E6.5-7.5) such as T, Tbx6, Fgf8, Tmprss2 are selectively upregulated in hypoxia (2-4 fold compared to normoxia), while ectoderm and pluripotency genes largely remain stable (Figure 1G). Genes that are later associated with node, notochord, and primitive gut development (Grosswendt et al., 2020) such as Krt19, Krt7, and Mixl1 are also upregulated, while those associated with brain and spinal cord development are downregulated. Thus, key mesoderm and endoderm lineage regulators appear to be specifically induced in hypoxic ES cells (Figure S1H). Taken together, stem cells present distinct temporal and cell type-specific transcriptional responses to hypoxia including lineage-specific genes. Importantly, these gene expression changes do not lead to spontaneous differentiation, they may however affect developmental trajectories later. Hereafter we focused on ES cells to investigate the hypoxia-associated activity of lineage-specific genes and its functional implications.

\section{WNT pathway genes are gradually upregulated during prolonged hypoxia}

The induction of T, Eomes, Tbx6, Lef1 among other genes points towards increased WNT pathway activity in hypoxia (Figure 1G, S2A), which was previously observed in cancer cells and linked to epithelial-mesenchymal transition (EMT) (Muz et al., 2015; Rankin and Giaccia, 2016). Of all Wnt genes, Wnt3, Wnt4, Wnt7a, and Wnt7b are significantly upregulated in hypoxic ES cells (Figure S2B). Wnt3 activity at the posterior primitive streak mediates EMT during gastrulation by upregulating downstream targets such as T, Eomes, Tbx6, etc. (Bardot and Hadjantonakis, 2020). To investigate the temporal dynamics of the WNT pathway activity and its relation to oxygen availability, we next cultured ES cells in normoxia or varying degrees of hypoxia for up to 7 days and collected samples at regular intervals (Figure 2A-C). Wnt3 and $\mathrm{T}$ are gradually upregulated in hypoxia with an up to $\sim 4$-fold increase over normoxia by day 7 (Figure 2B), while Eomes and Tbx6 are more modestly upregulated ( 1.5-fold). Pluripotency markers remain unchanged (Figure 2B, S2C). Importantly, Wnt3 and Eomes levels inversely correlate with oxygen availability, indicating association with an oxygen-mediated process (Figure 2C). Expression of pluripotency markers or oxidative phosphorylation genes does not correlate with oxygen levels, while glycolysis genes are expressed higher in more severe hypoxia (Figure S2D). Hypoxia- 
bioRxiv preprint doi: https://doi.org/10.1101/2021.07.21.452906; this version posted July 22, 2021. The copyright holder for this preprint (which was not certified by peer review) is the author/funder. All rights reserved. No reuse allowed without permission.

A

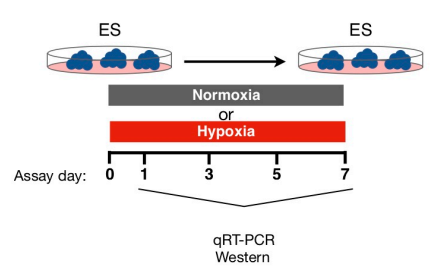

D

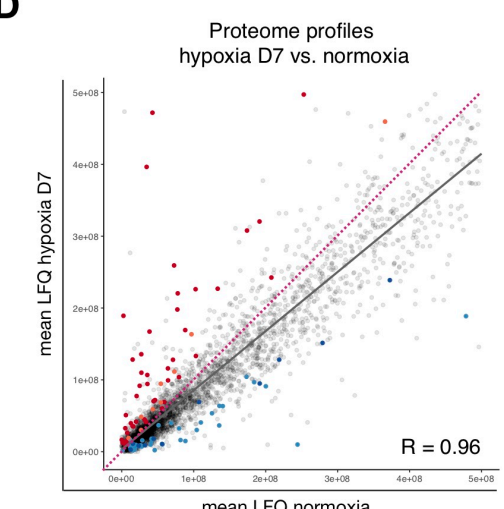

q-value $<0.1 \&>=0.05 \square$ upregulated $\square$ downregulated q-value $<0.05 \square$ upregulated $\square$ downregulated

$\mathbf{F}$

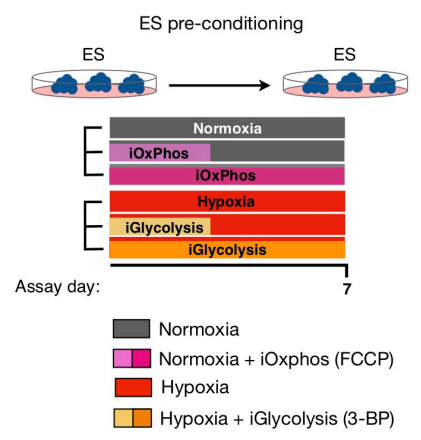

B

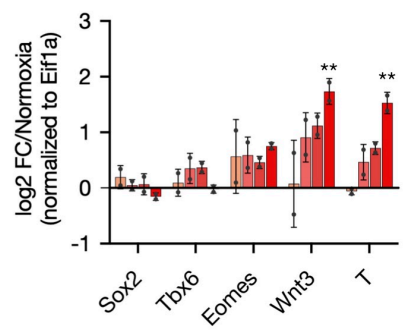

hypoxia: $\square$ Day $1 \square$ Day $3 \square$ Day $5 \square$ Day 7
C

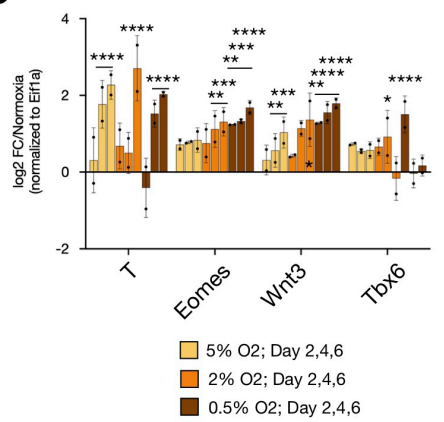

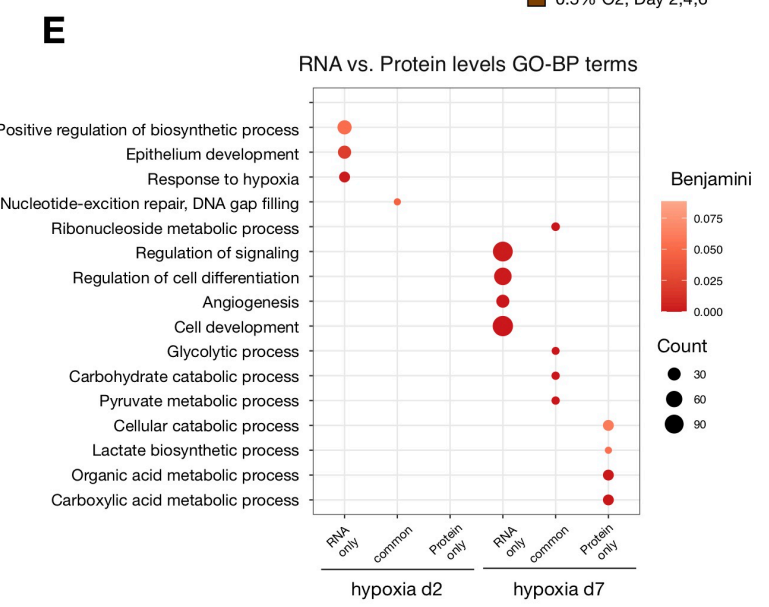

G

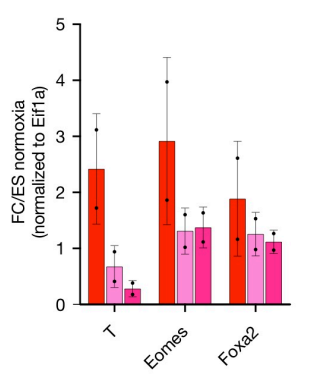

H

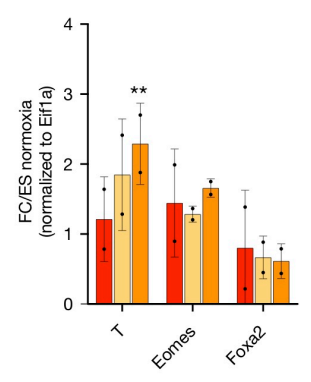

Figure 2. Transcriptional priming of ES cells towards differentiation in hypoxia by induction of WNT pathway genes.

A) Schematic of experimental setup corresponding to panel (b).

B) Relative expression levels of shown genes in hypoxic ES cells measured by RT-qPCR. Data represent log $\mathrm{FC}_{2}$ over normoxia normalized to Eif $1 \alpha$ and standard deviation for two biological replicates. Other tested genes are available in Figure S2C. The list of used primers is available in Table S10. The statistical test performed is a two-tailed paired Student's t-test.

C) Relative expression levels of shown genes in ES cells exposed to different levels of hypoxia measured by RT-qPCR. Data represent log ${ }_{2}$ FC over normoxia normalized to Eif1 $\alpha$ and standard deviation for two biological replicates. Other tested genes are available in Figure S2D. Statistical test performed is a two-way ANOVA.

D) Proteome profiles of hypoxic (d7) vs normoxic ES cells. Colored dots indicate differentially expressed proteins (|FC|>1.5, q-value $<0.05$ (dark red and blue) and q-value 0.05-0.1 (light red and blue)). Purple dotted line depicts the diagonal. LFQ, label-free quantification values. Complete proteome data and differentially expressed proteins (DEP) are available in Tables S3 and S4.

E) GO terms associated with identified DE transcripts and proteins in hypoxia. Representative significant terms are shown (Benjamini-Hochberg adjusted $p$-value $<0.1$ ). See Table S5 for full list of GO terms.

F) Schematic of experimental setup.

$\mathrm{G}, \mathrm{H}) \quad$ Relative expression levels of diagnostic genes in hypoxic ES cells vs normoxic ES cells treated with an oxidative phosphorylation inhibitor (G) or hypoxic ES cells treated with a glycolysis inhibitor $(\mathrm{H})$. Data represent $\log _{2} \mathrm{FC}$ over DMSO-treated normoxic ES cells normalized to Eif1 $\alpha$ and standard deviation for two biological replicates.

See also Figure S2. 
dependent induction of the Wnt pathway appears reversible, as expression levels of Wnt3, T, and Eomes revert to prior levels upon return of hypoxic cells to normoxia (Figure S2E). In hypoxia, WNT activity can be sustained for approximately 10 days, with Wnt3, T, Eomes, and Tbx6 transcript levels reverting to almost normoxic levels by day 16 (Figure S2E). HIF1 $\alpha$ depletion in the nucleus on day 16 may underlie this pattern (Figure S2F).

Oxygen depletion leads to curtailing of energydense processes including protein synthesis (Koumenis et al., 2002; Lee et al., 2020; Pettersen et al., 1986). To investigate whether differential expression at the transcript level is reflected at the protein level, we performed label-free mass spectrometry on ES cells in normoxia or exposed to acute or prolonged hypoxia (Figure 2D). Mass spectrometry identified 4260 proteins, of which $91.5 \%$ was also detected by RNA-seq (Figure S2G, proteome profiles are available in Table S3). In general, prolonged hypoxic ES cells retain a similar but globally downregulated proteome compared to normoxic ES cells (Spearman $R=0.96$, Figure 2D), with 63 and 43 proteins significantly up- or down-regulated (FC>1.5, qvalue < 0.05, Table S4). Differentially expressed proteins (DEP) on day 7 of hypoxia are enriched for metabolic genes (Figure 2E, Table S4, S5). In contrast, development- and differentiation-associated genes are differentially expressed mostly at the transcript but not protein level (Figure 2E). This may be due to the limited sensitivity of mass spectrometry or alternatively due to selective translation or degradation of specific gene transcripts. Western blotting of whole-cell extracts showed low level but gradually increasing expression of $T$ in hypoxic ES cells (Figure S2G), while Wnt3, Eomes, and Tbx6 could either not be detected or remained unaltered (data not shown). To assess whether $T$ is functional under these conditions in ES cells, we analyzed the expression levels of $T$ target genes (those bound and regulated by $T$ during in vitro primitive streak differentiation (Lolas et al., 2014)) in hypoxic ES cells (Figure $\mathrm{S} 2 \mathrm{H}$ ). Several DE genes are found among putative $\mathrm{T}$ target genes but constitute a small fraction $(4.25 \%)$. Furthermore, almost an equal number of putative $T$ target genes are upregulated on day 2 and day 7 . Since T induction at day 2 is modest ( 1.2-fold) at the transcript and protein level (Figure S2A, 2H), it is unlikely sufficient to directly activate downstream genes at that stage. In addition, putative T-activated genes are present among hypoxia-downregulated as well as hypoxiaupregulated genes (Figure $\mathrm{S} 2 \mathrm{H}$ ). We deduce that in ES cells hypoxia induces a transcriptional early primitive streak signature, which is not directly reflected at the protein level. As such, hypoxic ES cells do not resemble epiblast stem cells derived from the post-implantation embryos that comprise a mixture of T, FOXA2, and SOX2 expressing cells with anterior primitive streak characteristics (Kojima et al., 2014; Tsakiridis et al., 2014).

Glycolysis counteracts the hypoxiamediated early primitive streak signature A major component of hypoxia response is the switch of cellular metabolism from oxidative phosphorylation to glycolysis. Indeed, metabolic rewiring constitutes the main hypoxia response in ES cells at the protein level (Figure 2E). Metabolic pathways not only determine ways of energy utilization but also impact cellular states ( $\mathrm{Hu}$ et al., 2020; Rodriguez-Terrones et al., 2020). Therefore, we next set out to dissect the influence of glycolysis from other hypoxia-mediated events in the induction of early primitive streak genes. For this, we either induced glycolysis in normoxia (by inhibiting oxidative phosphorylation) or inhibited it in hypoxia acutely or continuously (Figure $2 \mathrm{~F}$ ). Induction of glycolysis in normoxia does not by itself induce T, Eomes, or Foxa2 expression and on the contrary decreases $T$ expression (Figure $2 G)$. Interestingly, inhibition of glycolysis in hypoxia further increases $T$ expression (Figure $2 \mathrm{H})$. Overall, $\mathrm{T}$ expression inversely correlates with the glycolytic state over time (Figure 2G, $H)$. These results suggest that $T$ levels in hypoxia are counteracted and balanced via a negative input of increased glycolysis, potentially enabling an early primitive streakprimed pluripotent state. HIF1 $\alpha$ mediates the transcriptional priming
in hypoxic ES cells
We next probed the primary hypoxia effector
HIF $1 \alpha$ for its potential regulation of early
primitive streak genes. To test whether HIF1
activation suffices to upregulate these genes, 
bioRxiv preprint doi: https://doi.org/10.1101/2021.07.21.452906; this version posted July 22, 2021. The copyright holder for this preprint (which was not certified by peer review) is the author/funder. All rights reserved. No reuse allowed without permission.

A

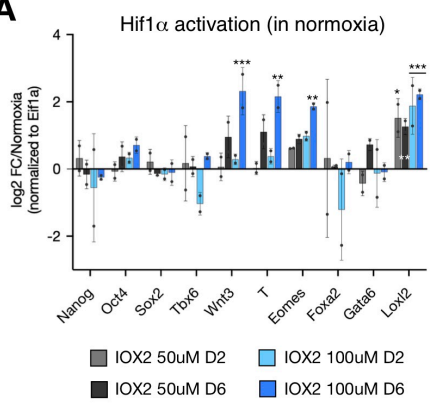

C
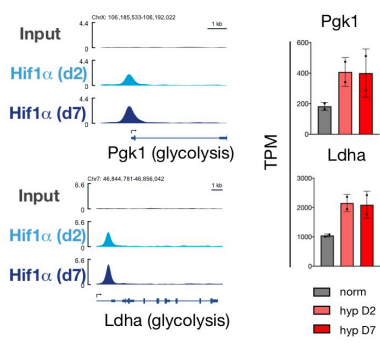

B

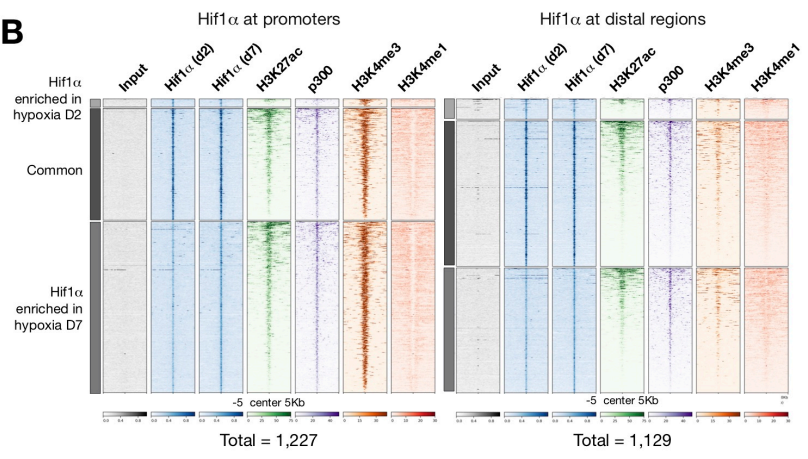

D

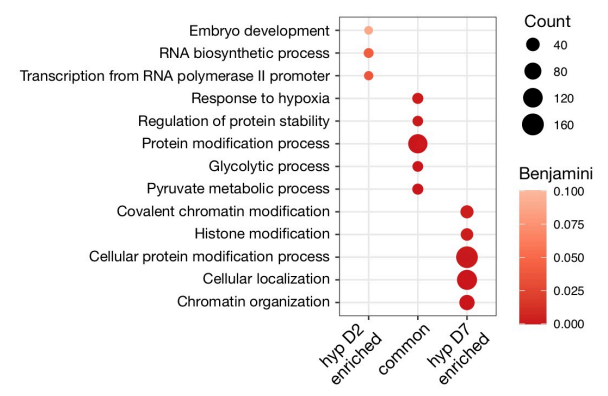

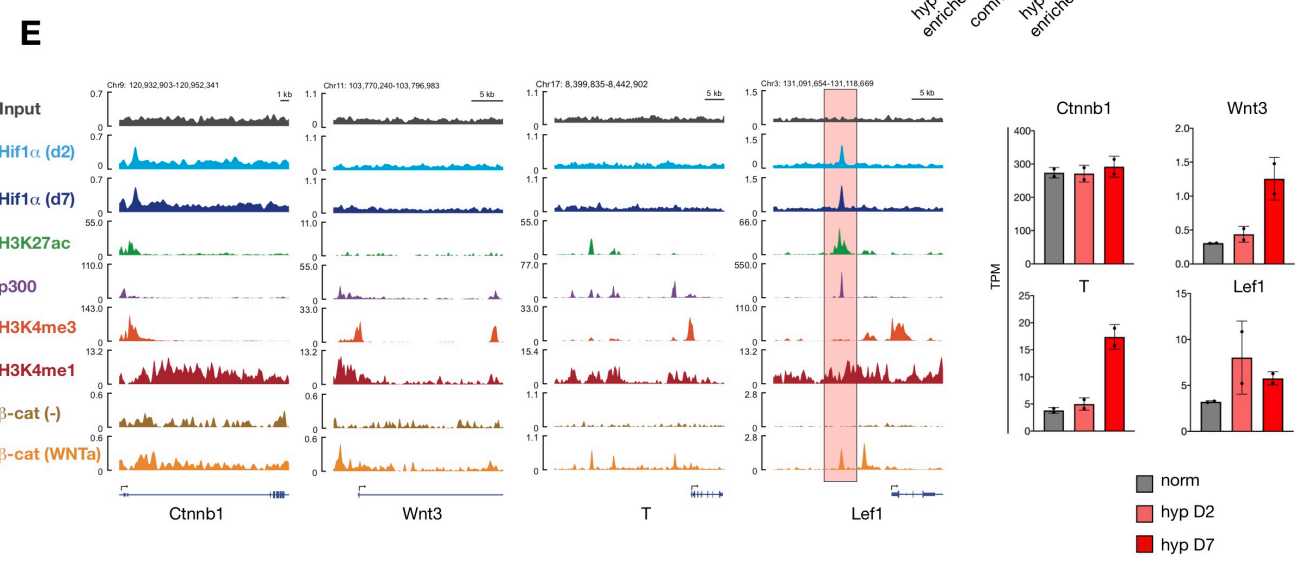

$\mathbf{F}$

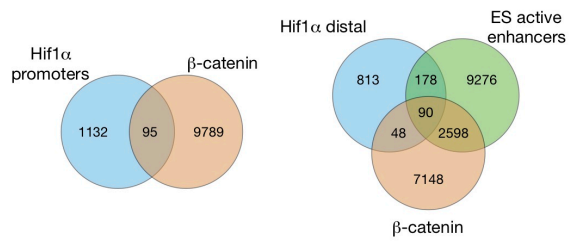

Figure 3. Hif1 $\alpha$ mediates induction of WNT pathway genes in ES cells.

A) Relative expression levels of shown genes in normoxic ES cells treated with the HIF1 $\alpha$ activator IOX2 at indicated concentrations for 2 or 6 days. Data represent $\log _{2} \mathrm{FC}$ over DMSO-treated ES cells normalized to Eif1 $\alpha$ and standard deviation for two biological replicates. Other tested genes are available in Figure S5A. The statistical test performed is two-way ANOVA.

B) Density plots showing enrichments of the indicated genes and histone modifications at Hif1 $\alpha$-bound promoters and distal regions. $\pm 5 \mathrm{~kb}$ surrounding peak center is shown. Numbers below the density plots indicate the total number of HIF1 $\alpha$-bound sites at day 2 and day 7 of hypoxia. For a complete list of peaks, see Table S6.

C) Genome browser views of HIF1 $\alpha$ binding at the promoters of shown glycolysis genes. The right panel shows expression values of the shown genes in normoxic and hypoxic ES cells as measured by RNA-seq.

D) GO-BP terms associated with HIF1 $\alpha$-target genes with HIF1 $\alpha$ binding at promoters. Representative significant terms are shown (BenjaminiHochberg adjusted p-value < 0.1). See Table S7 for the full list of GO terms.

E) Genome browser views of the indicated genes and histone modifications at canonical WNT pathway genes (left). Expression values of the shown genes in normoxic and hypoxic ES cells as measured by RNA-seq (right). Red highlight depicts an active enhancer in ES cells. $\beta$-CATENIN binding data was retrieved from (Zhang et al., 2013). Histone modification and p300 binding data and the lust of ES active enhancers were retrieved from (Cruz-Molina et al., 2017). WNTa, WNT activation as employed in (Zhang et al., 2013).

F) Venn diagrams showing the numbers of overlapping peaks with HIF1 $\alpha$ and $\beta$-CATENIN potential co-binding at promoters (left) and ES active enhancers.

See also Figure S3. 
we treated ES cells with IOX2 to inhibit the HIF $1 \alpha$ destabilizer prolyl hydroxylase 2 (Figure 3A) (Chowdhury et al., 2013; Murray et al., 2010). IOX2 treatment thus stabilizes HIF1 $\alpha$ in normoxia and allows to distinguish $\mathrm{HIF} 1 \alpha-$ mediated and other effects of hypoxia. Treatment of ES cells with IOX2 resulted in the induction of Wnt3, T, and Eomes in a dosedependent manner and at levels comparable to hypoxia (Figure 3A). Interestingly and similar to hypoxia, these genes are induced after prolonged treatment, while glycolysis genes are upregulated already on day 2 (Figure S3A).

To investigate whether developmental genes are induced via direct HIF $1 \alpha$ binding at promoters, we next profiled genomic binding sites of HIF $1 \alpha$ by ChIP-seq on day 2 and day 7 of hypoxia treatment. HIF $1 \alpha$ occupies promoters of 505 and 1,193 genes on day 2 and day 7 , of which 471 are shared and include canonical targets such as glycolysis genes (Figure 3B-D, Table S6). In general, HIF $1 \alpha$ continuously occupies glycolytic genes within the treatment time frame, while latertargeted genes are enriched for chromatin regulators (e.g., Eed and $\mathrm{Kdm} 4 \mathrm{c}$ ) and cellular localization genes (e.g., Prcc and Tpr) (Figure 3D, S3B, Table S7). However, HIF1 $\alpha$ binding at non-metabolic genes does not directly affect transcriptional output (Figure S3B). Only 39 out of 1,193 genes with $\mathrm{HIF} 1 \alpha$ enrichment at promoters on day 7 are significantly upregulated. We did not detect HIF $1 \alpha$ binding at promoters of WNT pathway effectors except for a significant but minor enrichment at the $\beta$ catenin promoter, which does not result in altered expression (Figure 3E and S3C).

Notably, HIF1 $\alpha$ also binds a comparable number of distal regions, some of which are enriched for H3K27 acetylation, H3K4me1, and p300 and are devoid of H3K4me3 in line with an enhancer signature (Figure 3B, Table S6) (Cruz-Molina et al., 2017). Although gene regulation by enhancers cannot be simply attributed to proximity in the linear genome, we find $\mathrm{HIF} 1 \alpha$ binding at regions proximal to several genes including the WNT effector TF Lef1 which is upregulated already on day 2 of hypoxia (Figure 3E, S3B). Lef1 is bound and activated by $\beta$-CATENIN upon WNT stimulation of ES cells but not in normal ES culture conditions (Figure 4E, compare $\beta$-catenin
(WNTa) vs $\beta$-catenin (control), data from (Zhang et al., 2013)). HIF1 $\alpha$ localization overlaps with the distal $\beta$-CATENIN binding site suggesting potential colocalization (Figure $3 \mathrm{E}$ ). More generally, HIF $1 \alpha$ and $\beta$-CATENIN share 95 target promoters and 90 target ES active enhancers (Figure 3F). We did not observe $\beta$ CATENIN stabilization or mainly nuclear localization in hypoxia as reported earlier (Mazumdar et al., 2010) (Figure S3D). These results suggest that HIF1 $\alpha$ mediates the induction of early primitive streak genes in hypoxia but mostly not by direct DNA binding.

\section{Hypoxia leads to global DNA demethylation through depletion of UHRF1}

Transcriptional control is exerted by TFs as well as modifiers of DNA and chromatin. While the hypoxic ES cell proteome is mostly stable, we noticed and confirmed the significant depletion of the DNA methyltransferase 1 (DNMT1) partner protein UHRF1 (Figure 4AC). Its transcript levels remain unchanged, ruling out direct transcriptional control (Figure S4A). HIF1 $\alpha$ activation in normoxia reduces UHRF1 levels, albeit to a lesser extent compared to hypoxia (Figure 4D, E), suggesting partial control by HIF1 $\alpha$. UHRF1 partners with DNMT1 for maintenance of DNA methylation during cell division (Bostick et al., 2007; Sharif et al., 2007). Although CG-rich gene promoters, including those of many developmental genes, are already depleted of DNA methylation, gene expression may be controlled by methylation of other regulatory elements such as enhancers (Feldmann et al., 2013; Stadler et al., 2011). Therefore, we investigated DNA methylation levels in ES cells exposed to acute (day 2) or prolonged hypoxia (day 7) by performing whole genome bisulfite sequencing (WGBS). Hypoxia exposure leads to a global decrease in DNA methylation, at a higher extent upon acute than prolonged exposure $(32 \%$ vs $7 \%)$ (Figure 4F). We observe increased expression of the de novo DNA methyltransferase DNMT3B in the remethylation time frame (Figure S4B). Expression of the TET DNA demethylases does not change, although their activity might be altered due to the inherent oxygen sensitivity (Figure S4B, Table S3) (Burr et al., 2017). DNA methylation is comparably reduced at most genomic features as well as at differentially expressed genes (Figure S4C-E). HIF $1 \alpha$ activation in normoxia via IOX2 
bioRxiv preprint doi: https://doi.org/10.1101/2021.07.21.452906; this version posted July 22, 2021. The copyright holder for this preprint (which was not certified by peer review) is the author/funder. All rights reserved. No reuse allowed without permission.

A

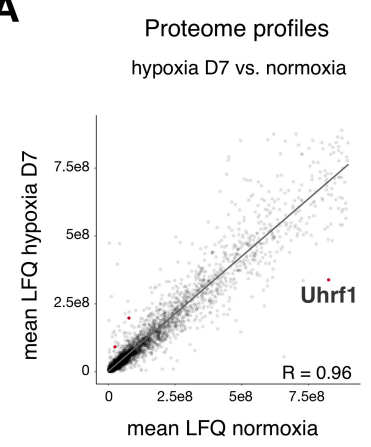

C

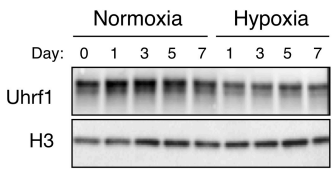

$\mathbf{E}$

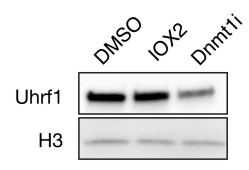

$\mathbf{F}$

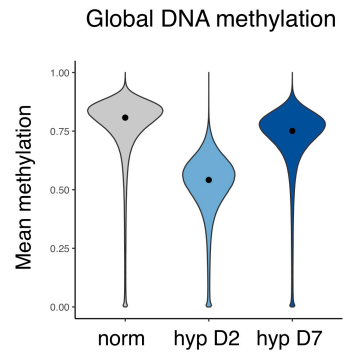

B

Uhrf1

hypoxia vs. normoxia
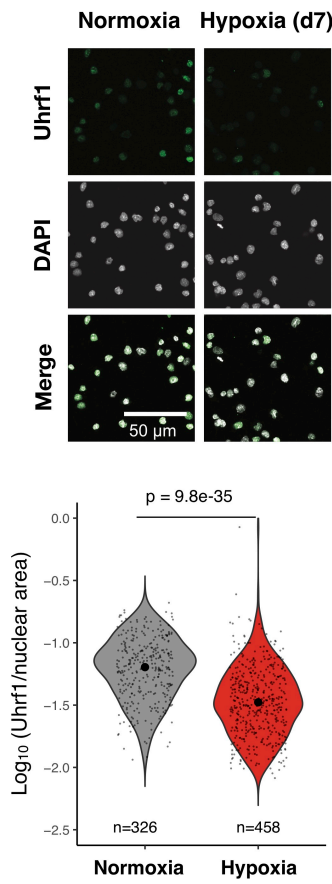

G

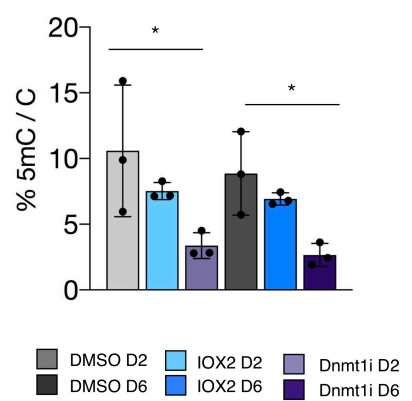

Uhrf1

IOX2 and Dnmt1i
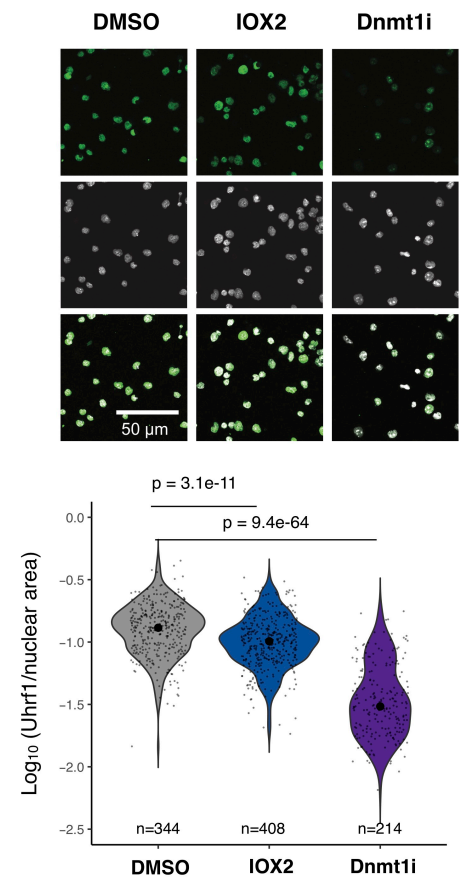

H

Dnmt1i (normoxia)

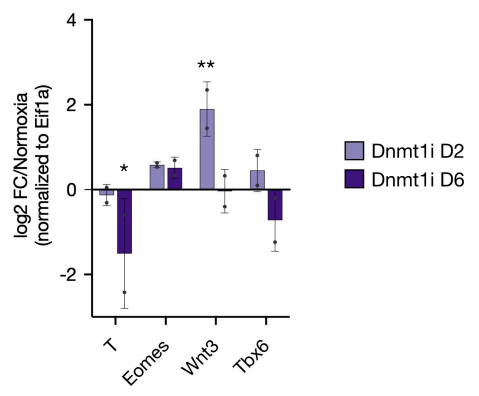

Figure 4. Depletion of Uhrf1 leads to global DNA demethylation in hypoxia.

A) Proteome profiles of hypoxic (d7) vs normoxic ES cells. Epigenetic regulators that are significantly altered at the protein level are highlighted. $\mathrm{LFQ}$, label-free quantification values.

B) IF images and quantifications of Uhrf1 in hypoxic (d6) and normoxic ES cells. Fluorescent intensity of each nucleus was measured and normalized to nuclear area. Each dot represents a cell. $\mathrm{N}$ represents number of cells quantified per sample. Statistical tests performed are unpaired two-sample Wilcoxon tests.

C) Western blots showing protein expression levels of Uhrf1 in normoxic and hypoxic ES cells. H3 was used as loading control.

D) IF images and quantifications of Uhrf1 in normoxic ES cells treated with the HIF1 $\alpha$ activator IOX2, a DNMT1 inhibitor, or DMSO as control. Fluorescent intensity of each nucleus was measured and normalized to nuclear area. Each dot represents a cell. $\mathrm{N}$ represents number of cells quantified per sample. Statistical tests performed are unpaired two-sample Wilcoxon tests.

E) Western blots showing protein expression levels of Uhrf1 in normoxic ES cells treated with the HIF1 $\alpha$ activator IOX2, a DNMT1 inhibitor, or DMSO as control (e). H3 was used as loading control.

F) Global DNA methylation levels in normoxic and hypoxic ES cells determined by WGBS. Data represent mean of two biological replicates.

G) DNA $5 \mathrm{mC}$ methylation levels in normoxic ES cells treated with the HIF1 $\alpha$ activator IOX2, a Dnmt1 inhibitor, or DMSO as control measured by mass spectrometry. Data represent $5 \mathrm{mC}$ normalized to total cytosine $(C)$ in three biological replicates. Statistical test performed is a one-way ANOVA.

H) Relative expression levels of shown genes in ES cells treated with the a DNMT1 inhibitor for 2 or 6 days. Data represent $\log _{2}$ FC over DMSOtreated ES cells normalized to Eif1 $\alpha$ and standard deviation for two biological replicates. Statistical test performed is a two-way ANOVA. P See also Figure S4. value style: $\left.\left.\left.p>0.05(n s), p<0.05\left(^{*}\right), p<0.01{ }^{(*}\right), p<0.001^{(* \star}\right), p<0.0001^{(* * *}\right)$. 
treatment only moderately decreases DNA methylation, similar to the limited response of UHRF1 (Figure 4D, G). To probe whether DNA demethylation in normoxia can induce WNT pathway genes, we cultured normoxic ES cells with a DNMT1 inhibitor for 2 or 6 days (Figure $4 \mathrm{H})$. DNA demethylation acutely induces Wnt3 but not downstream genes at the transcript level (Figure $4 \mathrm{H}$ ). These results suggest a potential additive effect of HIF1 $\alpha$ activity and DNA demethylation in hypoxia, which together with glycolysis shapes the transcriptional response at developmental genes.

\section{Hypoxic gastruloids spontaneously elongate in the absence of exogenous WNT activation}

To functionally test whether the hypoxiainduced early primitive streak signature enables emergence of cell states and tissues that resemble and arise from the primitive streak in vivo, we employed the gastruloid model. Aggregation of ES cells upon withdrawal of self-renewal factors results in embryoid bodies that contain cells corresponding to the three germ layers. Transient treatment of embryoid bodies generated from defined, low numbers of ES cells with the exogenous WNT activator CHIR99021 (Chi) between $48 \mathrm{~h}$ and $72 \mathrm{~h}$ of culture induces symmetry breaking and elongation and self-organization of the body axis, with polarized $\mathrm{T}$ expression at the posterior end (Beccari et al., 2018; Berge et al., 2008; Brink et al., 2014). Since hypoxia induces a transcriptional early primitive streak signature including Wnt3 and T, we reasoned that it might enable spontaneous elongation in the absence of exogenous WNT activation (termed '-Chi' hereafter). To test this possibility, we generated aggregates from 400 ES cells and scored $T$ expression, size and elongation index (Figure 5A-D). While structures cultured in normoxia throughout the procedure do not express $\mathrm{T}$ or spontaneously elongate in our hands, pre-conditioning of ES cells in hypoxia prior to aggregation induced $T$ expression and slight elongation (Figure 5B-D, S5A-B, compare $\mathrm{HN}$ to $\mathrm{NN}$ condition). Interestingly, exposure of structures to hypoxia only during differentiation led to stronger localized $T$ expression and more pronounced spontaneous elongation in a subset of structures (Figure 5B$\mathrm{D}, \mathrm{S} 5 \mathrm{~A}-\mathrm{B}, \mathrm{NH}$ condition).
To further probe $\mathrm{T}$ expression, elongation dynamics, and variability in -Chi structures, we performed a time- and spatially-resolved quantitative image analysis of 284 structures obtained in four independent experiments (Figure 5E-F, S5C-D). We observe a dispersed T expression starting at 48 hours and posterior confinement starting at 72 hours after aggregation in $\mathrm{NH}$ and $\mathrm{HN}$ gastruloids (Figure S5B). This results in the spontaneous elongation of $\sim 30 \%$ of the $\mathrm{NH}$ and $\mathrm{HN}$ aggregates (vs $0 \%$ in NN condition, Figure $5 \mathrm{~F}$, S5D). $T$ is most clearly induced and localized at the posterior end of the structure in the $\mathrm{NH}$ -Chi condition, although $\mathrm{HN}$-Chi structures also present low level T expression (Figure 5E, F). These findings suggest that exposure to hypoxia equips ES aggregates with the capacity to self-initiate the developmental events characteristic of the post-implantation embryo, including symmetry breaking, polarization and axial elongation, pointing to the importance of the microenvironment in shaping cell commitment and tissue morphogenesis.

Hypoxia modulates $T$ expression in conventional gastruloids

Although -Chi $\mathrm{HN}$ and, in particular, $\mathrm{NH}$ gastruloids can spontaneously break symmetry, polarize and elongate, gastruloid formation efficiency and elongation capacity is limited under these conditions. To test the effect of hypoxia in a more robust model of embryo development, we next combined hypoxia with exogenous activation of WNT (termed '+Chi' hereafter). In general, all +Chi structures elongate and show posterior $\mathrm{T}$ localization by $120 \mathrm{~h}$ after aggregation (Figure $6 \mathrm{~A}-\mathrm{B}, \mathrm{S} 6 \mathrm{~A}-\mathrm{C})$. Aggregation in hypoxia results in larger gastruloids (Figure 6B). Quantitative image analysis of 245 structures at $120 \mathrm{~h}$ after aggregation across four independent experiments revealed that hypoxia moderates $\mathrm{T}$ expression, but does not alter localization (compare HN to NN, Figure 6C, D). This effect was more pronounced at $96 \mathrm{~h}$, when not only overall $\mathrm{T}$ expression was lower but also more localized under all hypoxic conditions (Figure S6D, E). Intriguingly, direct comparison of $\mathrm{T}$ localization and intensity in +Chi and -Chi gastruloids revealed that in the subset of -Chi $\mathrm{NH}$ gastruloids that spontaneously elongate, $\mathrm{T}$ levels and localization are similar to those observed in +Chi gastruloids at $120 \mathrm{~h}$ (Figure 
A

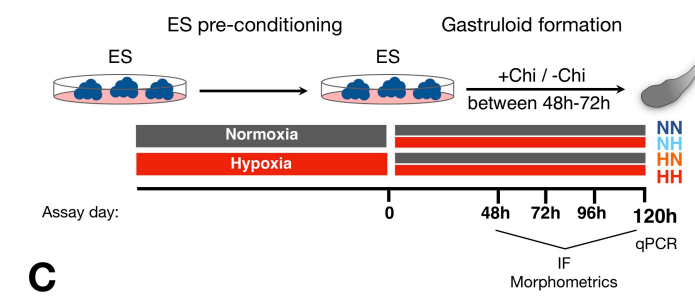

B

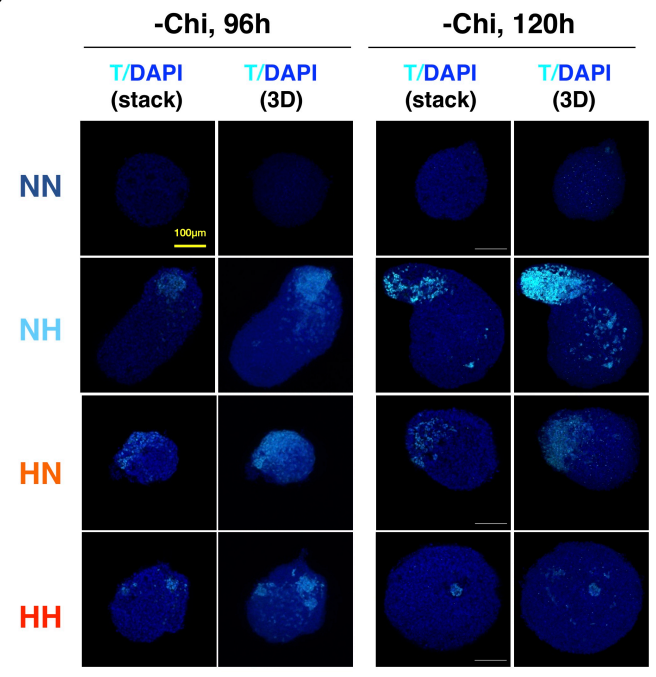

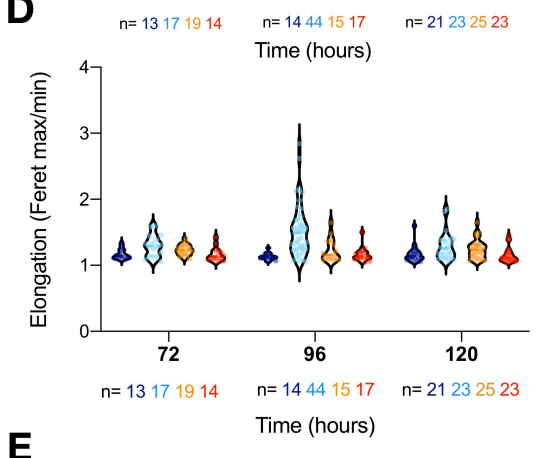

$\mathbf{E}$

\section{$\mathbf{F}$}
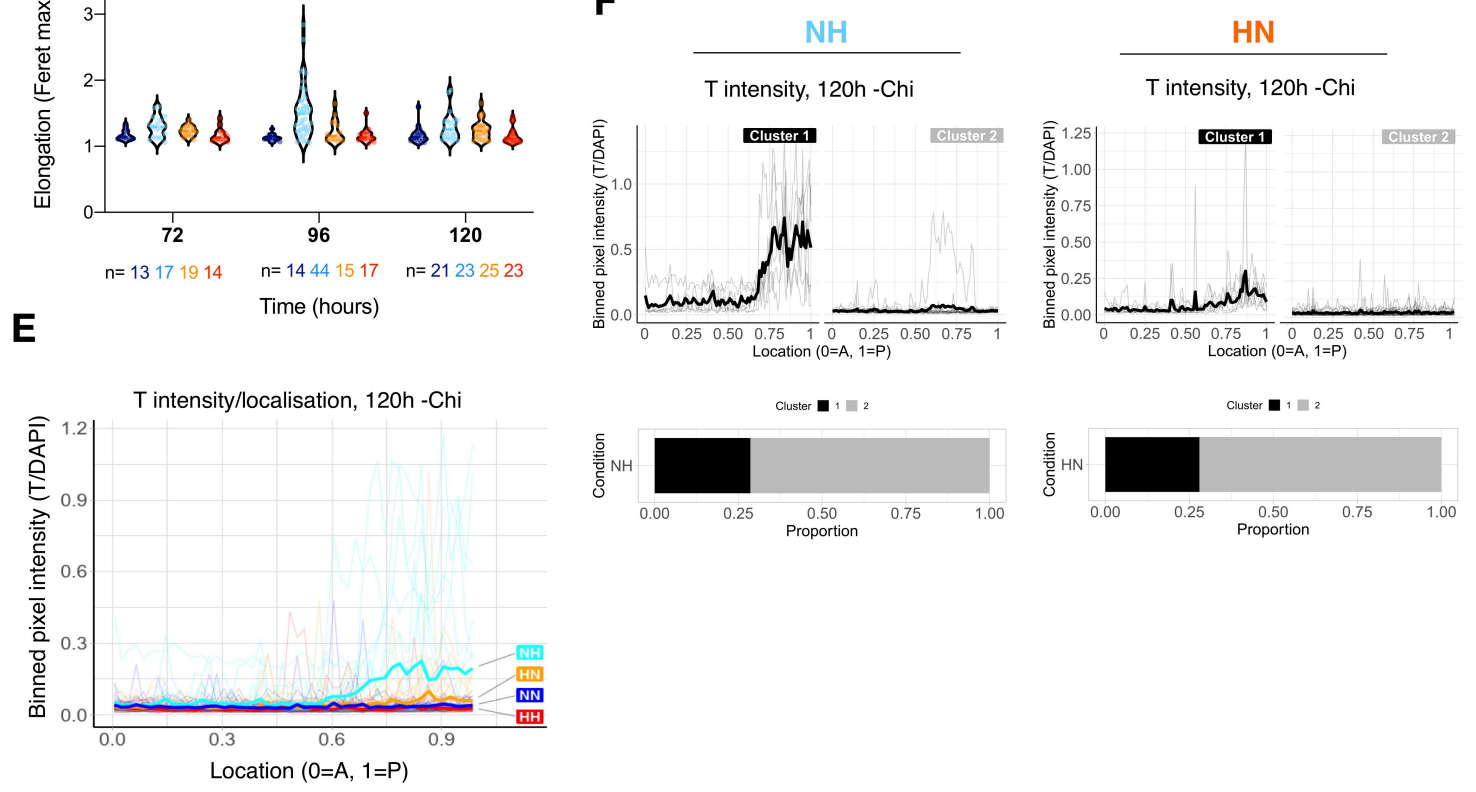

Figure 5. Hypoxia can induce spontaneous elongation of gastruloids in the absence of exogenous WNT activation.

A) Schematic of the experimental setup.

B) Confocal fluorescent microscopy images of representative -Chi gastruloids at 96h and 120h of culture. 3D, three-dimensional projection.

C) Area of gastruloids at each time point and condition. Fluorescent images were used for quantifications. Each dot indicates a single structure and $\mathrm{n}$ indicates the number of analyzed structures at each time point and condition.

D) Elongation index (defined as aspect ratio ferret max / feter min) of gastruloids at each time point and condition. Fluorescent images were used for quantifications. Each dot indicates a single structure and $n$ indicates the number of analyzed structures at each time point and condition. Note the bimodality of the data, especially for the $\mathrm{NH}$ condition, with the structures with a higher index reflecting the proportion of gastruloids that spontaneously elongate.

E) Localization of $\mathrm{T}$ signal along the anterior-posterior (A-P) axis of gastruloids in each condition at $120 \mathrm{~h}$ of culture. $\mathrm{T}$ signal normalized to DAPI and binned at $1 \%$ length increments along each structure for plotting. See Methods for details. Thick lines show mean values and thin lines show data from individual structures.

F) K-means clustering of the $\mathrm{NH}$ and $\mathrm{HN}$ structures presented in $\mathrm{E}$ ) with $\mathrm{n}=2$ clusters.

See also Figure S5.

$6 \mathrm{E})$. In contrast, hyper-induction of $\mathrm{T}$ is seen in $\sim 15 \%$ of + Chi gastruloids but none of the - Chi $\mathrm{NH}$ gastruloids (Figure 4E). Notably, T expression dynamics resulting in its polarized expression are different in -Chi vs +Chi gastruloids. Whereas in -Chi gastruloids $T$ is spontaneously induced in a small cluster of cells and becomes polarized at $72 \mathrm{~h}$; in +Chi 
bioRxiv preprint doi: https://doi.org/10.1101/2021.07.21.452906; this version posted July 22, 2021. The copyright holder for this preprint (which was not certified by peer review) is the author/funder. All rights reserved. No reuse allowed without permission.
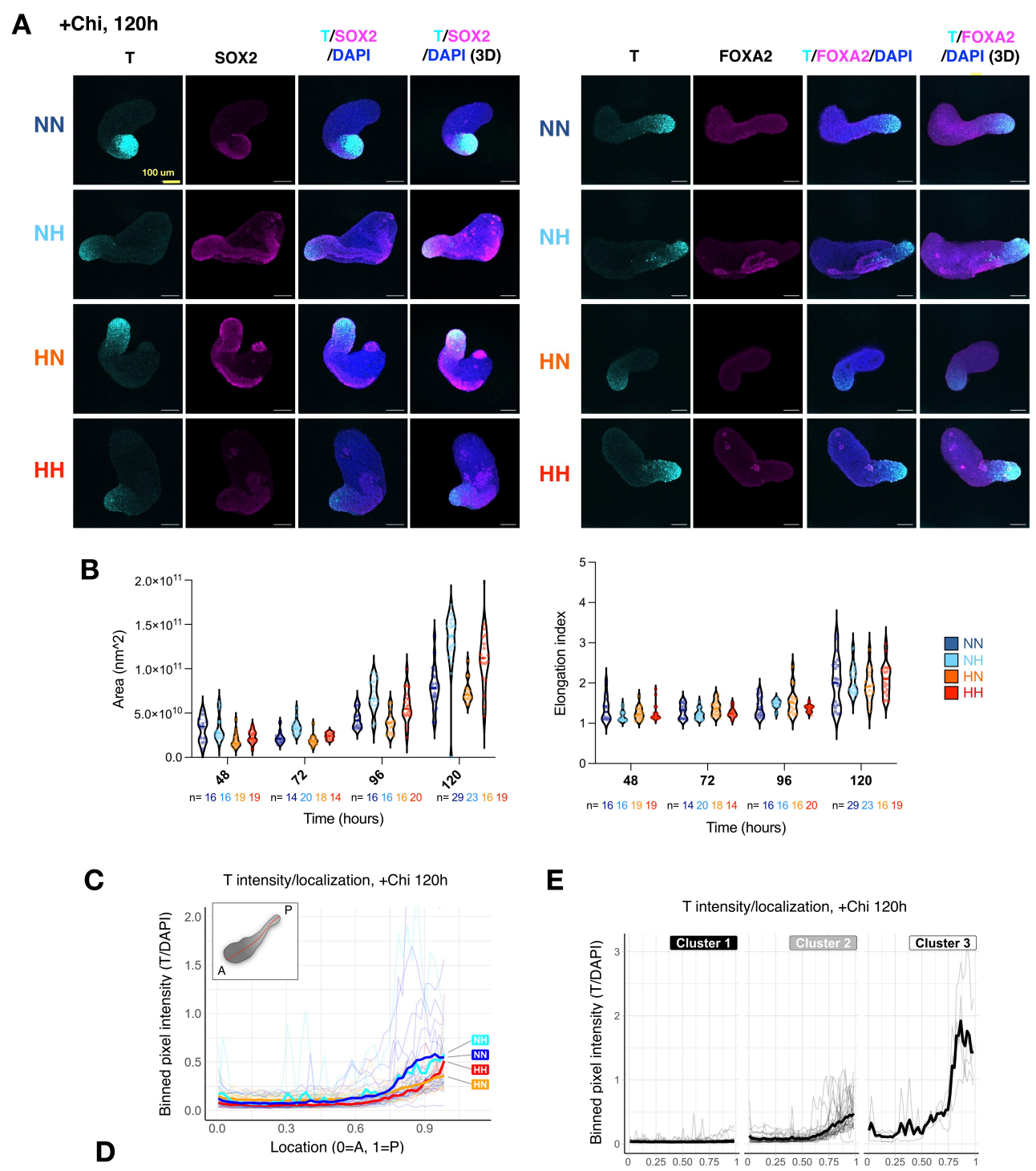

$\mathbf{E}$

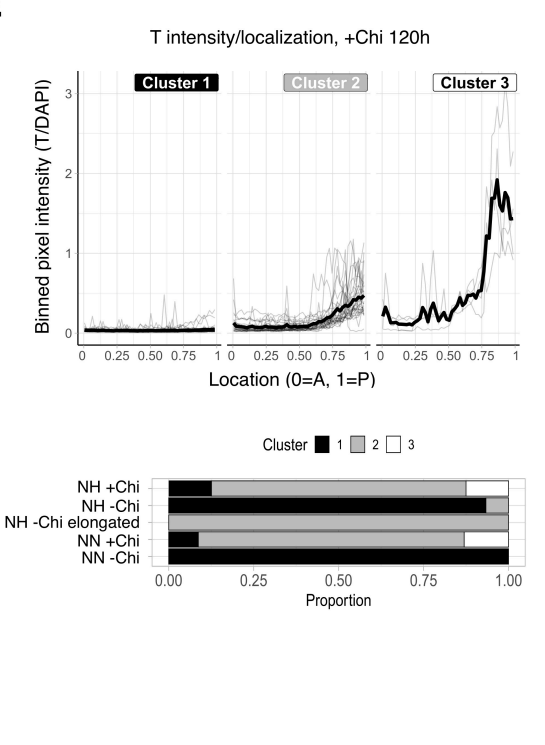

Figure 6. Hypoxia modulates T levels in conventional (+Chi) gastruloids.

A) Confocal fluorescent microscopy images of representative +Chi gastruloids at $120 \mathrm{~h}$ of culture. Images show a single z-stack, except those labeled 3D, which show 3D maximum intensity projections of the gastruloid. Additional structures are available in Figure S6C.

B) Area and elongation index (defined as aspect ratio ferret $\max /$ ferret $\min$ ) of + Chi gastruloids at each time point and condition. Fluorescent images were used for quantifications. Each dot indicates a single structure and $\mathrm{n}$ indicates the number of analyzed structures at each time point and condition.

C, D) Localization of T signal along the anterior-posterior (A-P) axis of gastruloids in each condition. T signal was binned at $1 \%$ length increments along each structure for plotting. T intensity was normalized to DAPI stain, then was either plotted as such (C) or was further fitted in a 0-1 scale (D). See Methods for details. Thick lines show the mean and thin lines show data from individual structures.

E) K-means clustering of all $120 \mathrm{~h}+$ Chi structures plotted in C) with $\mathrm{n}=3$ clusters.

See also Figure S6. 
A

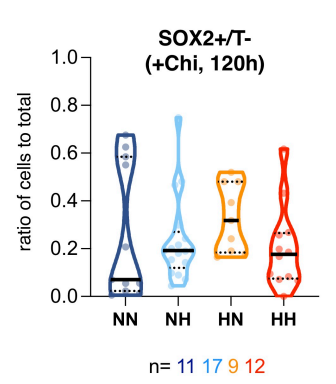

B

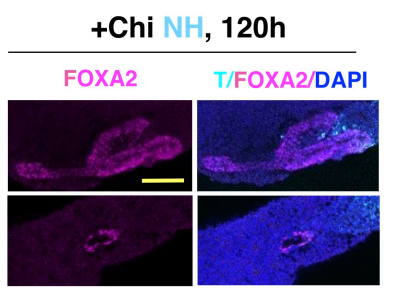

C

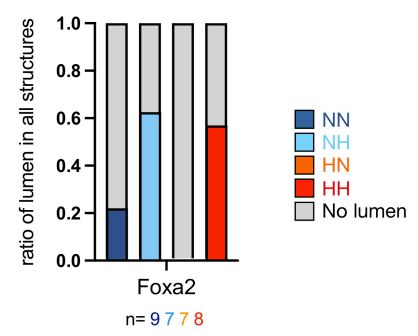

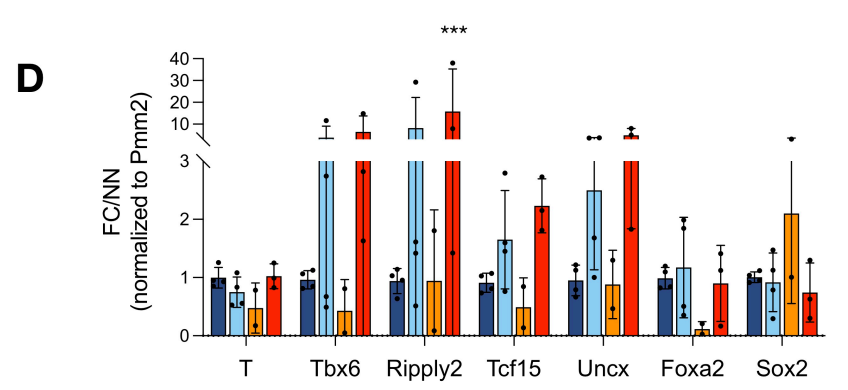

$\mathbf{E}$

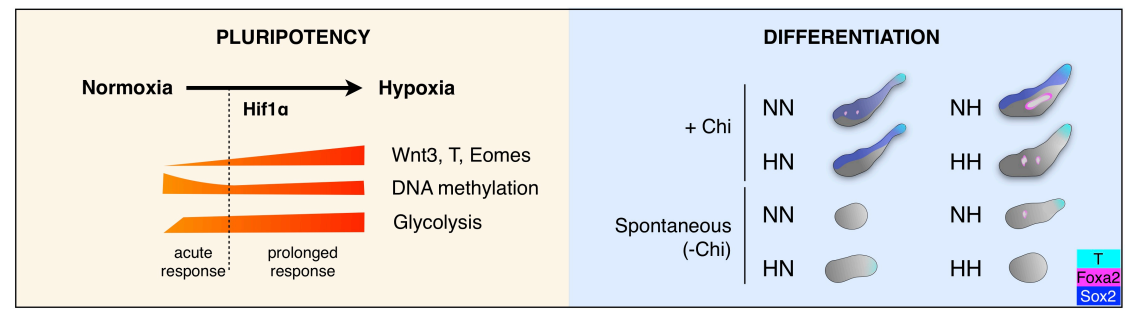

Figure 7. Hypoxia enhances lineage representation in conventional gastruloids.

A) Proportion of SOX2 single positive cells in all quantified cells in each structure. Each gastruloid was quantified at the single-cell level for the presence of T/SOX2 staining. Each dot indicates a single structure. Thick lines indicate median and broken lines indicate quartiles.

B) Confocal images of gastruloids showing gut tube-like structures. Scale bar is $100 \mu \mathrm{m}$.

C) The ratio of structures containing a lumen surrounded by FOXA2 staining. $\mathrm{n}$ indicates number of analyzed structures in each condition.

D) Relative expression levels of the indicated genes in normoxic or hypoxic gastruloids at 120h. Data represent FC over NN normalized to Pmm2 and standard deviation for 2-4 biological replicates. Each dot presents a biological replicate consisting of three pooled gastruloids.

E) Working model of the components of acute and prolonged hypoxia response in ES cells and the outcome of exposure to hypoxia on differentiation of gastruloids.

gastruloids $\mathrm{T}$ is initially induced in most cells by $72 \mathrm{~h}$ and is later polarized at $96 \mathrm{~h}$ (compare Figure S5B to S6B). Taken together, the distinct mode of induction and expression dynamics of $\mathrm{T}$ might reflect the ability of hypoxia to provoke a physiological localized induction of $T$, whereas exogenous WNT induction might result in polarized T expression through both physiological and nonphysiological phenomena.

Enhanced representation of germ layer markers in conventional gastruloids cultured in hypoxia

Conventional + Chi gastruloids display localized $\mathrm{T}$ expression at the posterior end and at $120 \mathrm{~h}$ contain a variety of cell states reminiscent of the post-occipital E8.5 embryo (Beccari et al., 2018; Berge et al., 2008; Brink et al., 2014; Turner et al., 2017; Vianello and Lutolf, 2020). However, the uniform application of a strong WNT signal in the conventional protocol is nonphysiological, and might limit tissue diversification in gastruloids. To assess the relative abundance of cells representing the different germ layers in hypoxia, we stained +Chi gastruloids with SOX2 (as neuroectoderm marker), FOXA2 (as endoderm marker) in addition to $T$ and analyzed their expression levels and patterns (Figure 6A, S6B-C, 7A-D). Conventional +Chi gastruloids cultured in normoxia throughout the procedure 
present substantial variability in expression patterns of SOX2 and FOXA2 (NN condition, Figure 6A, S6B-C). In our hands, SOX2 expression either covers the entire A-P axis or remains localized to the posterior end and FOXA2 expression remains minimal (Figure 6A, S6B, 7A-B). However, hypoxia exposure increases the proportion of SOX2+/T- cells as identified by single cell image analysis (Figure 7A). Remarkably, we identify FOXA2+/T- cells that self-organize around a lumen in a subset of the $\mathrm{HN}$ and $\mathrm{NH}$ gastruloids, reminiscent of development of the gut tube (Figure 7B, C). Quantitative expression analysis revealed that (pre)somitic mesoderm ((P)SM) marker genes Tbx6, Ripply2, Tcf15 and Uncx were also upregulated in gastruloids cultured under hypoxic conditions, independent on the ESC starting state (compare $\mathrm{NH}$ to $\mathrm{NN}$ and $\mathrm{HH}$ to $\mathrm{HN}$ in Figure 7D). In conclusion, these data show that i) hypoxic pre-conditioning of ES cells increases the induction of neuroectoderm in conventional gastruloids; ii) culture of gastruloids under hypoxic conditions enhance the levels of $(\mathrm{P}(\mathrm{SM}))$ and endodermal markers in conventional gastruloids; and iii) hypoxia can be sufficient to induce $T$ expression and spontaneous elongation in -Chi gastruloids. Thus, hypoxia could potentially be harnessed in the culture of models of embryo development as a physiologically relevant means to induce axial elongation and improve germ layer representation.

\section{DISCUSSION}

In this study, we present hypoxia as a critical microenvironmental factor shaping cell fate decisions in early stem cells. We show that hypoxia promotes a transcriptional early primitive streak signature in ES cells in a HIF1 $\alpha$-associated manner. In 3D gastruloids, hypoxia governs both cell fate decisions and tissue morphogenesis, leading to enhanced germ layer representation and spontaneous embryo-like morphogenetic events in the absence of exogenous WNT activation (Figure 7E). In extraembryonic stem cells, hypoxia induces transcriptional responses distinct from ES cells. Particularly, the significant decrease in Cdx2 expression in TS cells might favor a mural TE identity (Frias-Aldeguer et al., 2020). Interestingly, developmental genes appear to be responsive to hypoxia in all three cell types.
Whether this response also alters differentiation capacity of TS and XEN cells and how this would impact cellular crosstalk in co-culture systems are also of relevance to models of embryo development. We find that the ES cell epigenetic landscapes undergo major rewiring in response to hypoxia at least at the level of DNA demethylation. Additionally, several chromatin modifiers including Eed and Kdm4c show significant fluctuations at the protein level in response to hypoxia (Table S3, S4). Whether this results in further rewiring of the chromatin landscape and a potential interplay with DNA demethylation remains open. Increased glycolysis, a major component of hypoxia response, hampers the expression of lineage genes and counteracts Hif1mediated induction of WNT pathway genes. In this context, glycolysis vs Wnt upregulation might achieve a balance in keeping transcriptionally-primed ES cells in the pluripotent state under hypoxic culture conditions.

Transcriptional induction of the WNT pathway in hypoxic ES cells is mediated by HIF1 $\alpha$ activity, however, we do not detect direct HIF1 $\alpha$ binding at promoters of Wnt3, T, Eomes, etc. Instead, HIF $1 \alpha$ binds to active ES enhancers and could potentially co-localize with $\beta$-CATENIN. HIF1 $\alpha$ binding at enhancers was previously observed in cancer cells (Andrysik et al., 2021; Platt et al., 2016). Here we show HIF1 $\alpha$ binding at ES enhancers for the first time. Similarly, induction of various WNT responses by HIF $1 \alpha$ has been widely documented in tumors and is associated with EMT and poor prognosis (Mori et al., 2016; Muz et al., 2015; Rankin and Giaccia, 2016; Schwab et al., 2012). Pluripotent and cancer cells are both fast-proliferating cells that share regulatory landscapes (Manzo, 2019). Therefore, it is conceivable that growth factors or regulators elicit similar responses in ES and cancer cells.

Hif1 $\alpha \mathrm{KO}$ is embryonic lethal at E9.5-10.5 due to neural tube defects and other embryonic abnormalities, together with placental defects largely attributable to defective angiogenesis (Kozak et al., 1997). Based on our data, these complex pathologies could indeed be rooted in events at much earlier stages of development. Mapping of lineage distribution in Hif1 $\alpha \mathrm{KO}$ embryos at gastrulation stages (E6.5-E9.5) at 
the single-cell level is required to reveal its control over lineage commitment. More broadly, HIF $1 \alpha$ activity at canonical and noncanonical targets affects lineage choices in a cell type-dependent manner in health and disease (Allan et al., 2021; Lie et al., 2005; Shao et al., 2021). As such, hypoxia likely finetunes many developmental processes rather than altering developmental trajectories. Further understanding of the underlying mechanisms will inform strategies to harness this microenvironmental factor in models of embryo development.

The overall impact of hypoxia on development likely combines HIF1 $\alpha$-mediated and unrelated processes and encompasses altered epigenetic, transcriptional, and translational programs. For example, here we observe that most transcriptional changes are not reflected at the protein level, hinting at translational or post-transcriptional regulation. Translation has been shown to be globally suppressed in hypoxic cells (Koumenis et al., 2002; Pettersen et al., 1986). Translational profiling, e.g., via ribosome profiling, will likely identify selective translation as a regulator of ES self-renewal and differentiation under hypoxic conditions. On the other hand, part of the hypoxic response in ES cells is selective protein degradation as evidenced by gradual depletion of UHRF1 despite unaltered transcript levels (Figure 4A-C, Table S1). Which sequence features or protein associations mediate such selective degradation warrants further exploration. In addition to mediating DNA methylation, UHRF1 was shown to induce glycolysis, HIF1 $\alpha$ expression, and EMT genes in cancers (Hu et al., 2019; Kim et al., 2017). We show here that UHRF1 is dynamically regulated in response to HIF $1 \alpha$ activation and DNA demethylation (Figure 4D, E), however, whether UHRF1 levels influence glycolysis or EMT genes independent of DNA methylation remains to be further explored.

By testing the impact of hypoxia on lineage choices through gastruloid formation assays, here we show that hypoxia may act as a physiologically relevant means to induce symmetry breaking, polarization and axial elongation. Following these findings, hypoxia could be combined with a milder exogenous WNT activation to generate gastruloids that more closely mimic the embryo, and/or harnessed in other models of mouse postimplantation or human development (Moris et al., 2020; Olmsted and Paluh, 2021; Veenvliet et al., 2020; Xu et al., 2021). Particularly, the increased expression of (P)SM markers in hypoxic gastruloids suggests that hypoxia can be utilized to shift the decision making process of the bipotential neuromesodermal progenitors (NMPs) that contribute cells to both neural tube and somites in vivo (Koch et al., 2017; Tzouanacou et al., 2009). In trunk-like structures, in which neural tube and somite formation is unlocked by embedding gastruloids in low percentage matrigel, about $50 \%$ of the structures display a neural bias, with no clear somite formation, whereas in the other $50 \%$ formed somites are smaller than their in vivo counterparts and over time the propensity of NMPs to contribute to the somitic tissue vastly decreases (Veenvliet and Herrmann, 2021; Veenvliet et al., 2020). It will thus be of great interest to test if hypoxia can improve TLS formation.

The direct comparison of $-\mathrm{Chi}$ and +Chi gastruloids suggests that the developmental modes underlying $\mathrm{T}$ induction, symmetry breaking, polarization and axial elongation are distinct, with the non-uniform $\mathrm{T}$ induction in hypoxic -Chi gastruloids presumably more reliably recapitulating embryo dynamics. Interestingly, such non-uniform polarized $\mathrm{T}$ induction has been described in two recently published alternative gastruloid protocols, and in both cases leads to more complete models of embryo development, that include the cephalic tissues (Girgin et al., 2021; Xu et al., 2021). It will thus be interesting to see if cephalic tissues arise in hypoxic -Chi gastruloids.

Under our culture conditions, hypoxia has a clear endoderm-enhancing effect, in line with what has been reported for spontaneous and directed differentiation of mouse ES cells towards definitive endoderm (Pimton et al., 2015). The efficiency of endoderm induction in conventional gastruloids is currently subject to high variation. Whereas some studies have reported the formation of gut primordia in gastruloids, in other reports mainly neural and mesodermal tissue is formed (Beccari et al., 2018; Brink et al., 2020; Turner et al., 2017; Veenvliet et al., 2020; Vianello and Lutolf, 2020). Although the reason for this is unclear, 
the variation may be rooted in ES genetic backgrounds and/or pluripotency conditions, both linked to the propensity to form the different germ layers in gastruloids (Veenvliet and Herrmann, 2021). We therefore envision that hypoxia could be harnessed to more robustly induce gut primordia in gastruloids and other models of embryo development. Moreover, it will be of great interest to dissect how cell-intrinsic features (e.g. genetic background) interact with ESC pluripotency conditions and metabolic inputs (e.g. oxygen tension) in future studies.

Overall, our gastruloid data point to the importance of using physiologically relevant oxygen concentrations in models of embryo development. This is further corroborated by recent studies demonstrating that hypoxic culture conditions increase both the efficiency of the formation of blastocyst-like structures from human and mouse pluripotent stem cells, and ex utero culture of embryos from postimplantation to early organogenesis stages (Aguilera-Castrejon et al., 2021; Sozen et al., 2019, 2021). Thus, in addition to other modulators of the microenvironment such as medium composition, and matrix, we suggest oxygen tension to be taken into consideration when modelling developmental processes in a dish, or culturing mammalian embryos ex utero.

\section{ACKNOWLEDGMENTS}

We thank members of the Bulut-Karslioglu Lab and Denes Hnisz for critical feedback, MPIMG sequencing, and imaging facilities for technical help and discussions. We thank Jennifer Shay for lab organization and assistance, Cordula Mancini for assistance, Beata LukaszewskaMcGreal for proteome sample preparation, Jalees Rehman (University of Illinois) for providing cell lines for initial characterization, Bernhard Herrmann for providing lab and office space, Thorsten Mielke and Beatrix Fauler for assistance with image acquisition. This project was supported by the Max Planck Society (D.M., A.M., J.V.V., A.B.-K.) a Bundesinstitut für Risikobewertung Bf3R grant No. 60-0102-01.P589 (J.V.V.) and the Sofja Kovalevskaja Award (Humboldt Foundation) to A.B.-K.

\section{AUTHOR CONTRIBUTIONS}

A.B.-K. conceived the project. M.T. made initial observations and collected RNA-seq samples. S.I.G. performed the gastruloid experiments and analyzed the data together with R.B. and J.V.V. under the supervision of J.V.V.. M.S. performed IFS and TS and XEN characterization. I.V. performed metabolic analysis. A.L.M. prepared WGBS samples and S.H. performed WGBS analysis under the supervision of A.M.. B.K. and D.A. performed initial differentiation assays. R.C. helped with initial characterization of Hif1 $\alpha$ pathway under the supervision of I.B. D.M. supervised mass spectrometry experiments. All other experiments and analyses were performed by N.L.A. with help from R.M.-R.. A.B.-K. supervised the project. J.V.V. and A.B.-K. wrote the manuscript with feedback from all authors.

\section{DECLARATION OF INTERESTS}

The authors declare no competing interests.

\section{DATA AVAILABILITY}

RNA-seq, ChIP-seq and WGBS data generated in this study has been deposited to the GEO database under the accession number GSE178628. Proteomics data has been deposited to PRIDE database under the accession number PXD026641. Full datasets will be released after publication. 


\section{REFERENCES}

Aguilera-Castrejon, A., Oldak, B., Shani, T., Ghanem, N., Itzkovich, C., Slomovich, S., Tarazi, S., Bayerl, J., Chugaeva, V., Ayyash, M., et al. (2021). Ex utero mouse embryogenesis from pre-gastrulation to late organogenesis. Nature 593, 119-124.

Allan, K.C., Hu, L.R., Scavuzzo, M.A., Morton, A.R., Gevorgyan, A.S., Cohn, E.F., Clayton, B.L.L., Bederman, I.R., Hung, S., Bartels, C.F., et al. (2021). Non-canonical Targets of HIF1a Impair Oligodendrocyte Progenitor Cell Function. Cell Stem Cell 28, 257-272.e11.

Andrysik, Z., Bender, H., Galbraith, M.D., and Espinosa, J.M. (2021). Multi-omics analysis reveals contextual tumor suppressive and oncogenic gene modules within the acute hypoxic response. Nat Commun 12, 1375.

Bardot, E.S., and Hadjantonakis, A.-K. (2020). Mouse gastrulation: Coordination of tissue patterning, specification and diversification of cell fate. Mech Develop 163, 103617.

Batt, P., Gardner, D., and Cameron, A. (1991). Oxygen concentration and protein source affect the development of preimplantation goat embryos in vitro. Reproduction Fertility Dev 3, 601-607.

Beccari, L., Moris, N., Girgin, M., Turner, D.A., BaillieJohnson, P., Cossy, A.-C., Lutolf, M.P., Duboule, D., and Arias, A.M. (2018). Multi-axial self-organization properties of mouse embryonic stem cells into gastruloids. Nature 562, 272-276.

Berge, D. ten, Koole, W., Fuerer, C., Fish, M., Eroglu, E., and Nusse, R. (2008). Wnt Signaling Mediates SelfOrganization and Axis Formation in Embryoid Bodies. Cell Stem Cell 3, 508-518.

Berge, D. ten, Kurek, D., Blauwkamp, T., Koole, W., Maas, A., Eroglu, E., Siu, R.K., and Nusse, R. (2011). Embryonic stem cells require Wnt proteins to prevent differentiation to epiblast stem cells. Nat Cell Biol 13, 1070-1075.

Bostick, M., Kim, J.K., Estève, P.-O., Clark, A., Pradhan, S., and Jacobsen, S.E. (2007). UHRF1 Plays a Role in Maintaining DNA Methylation in Mammalian Cells. Science 317, 1760-1764.

Brink, S.C. van den, Baillie-Johnson, P., Balayo, T., Hadjantonakis, A.-K., Nowotschin, S., Turner, D.A., and Arias, A.M. (2014). Symmetry breaking, germ layer specification and axial organisation in aggregates of mouse embryonic stem cells. Development 141, 42314242.

Brink, S.C. van den, Alemany, A., Batenburg, V. van, Moris, N., Blotenburg, M., Vivié, J., Baillie-Johnson, P., Nichols, J., Sonnen, K.F., Arias, A.M., et al. (2020). Single-cell and spatial transcriptomics reveal somitogenesis in gastruloids. Nature 582, 405-409.

Brookes, E., Santiago, I. de, Hebenstreit, D., Morris, K.J., Carroll, T., Xie, S.Q., Stock, J.K., Heidemann, M., Eick, D., Nozaki, N., et al. (2012). Polycomb associates genome-wide with a specific RNA polymerase II variant, and regulates metabolic genes in ESCs. Cell Stem Cell 10, 157-170.
Burr, S., Caldwell, A., Chong, M., Beretta, M., Metcalf, S., Hancock, M., Arno, M., Balu, S., Kropf, V.L., Mistry, R.K., et al. (2017). Oxygen gradients can determine epigenetic asymmetry and cellular differentiation via differential regulation of Tet activity in embryonic stem cells. Nucleic Acids Res 46, gkx1197-.

Carpenter, A.E., Jones, T.R., Lamprecht, M.R., Clarke, C., Kang, I.H., Friman, O., Guertin, D.A., Chang, J.H., Lindquist, R.A., Moffat, J., et al. (2006). CellProfiler: image analysis software for identifying and quantifying cell phenotypes. Genome Biology 7, R100.

Chowdhury, R., Candela-Lena, J.I., Chan, M.C., Greenald, D.J., Yeoh, K.K., Tian, Y.-M., McDonough, M.A., Tumber, A., Rose, N.R., Conejo-Garcia, A., et al. (2013). Selective Small Molecule Probes for the Hypoxia Inducible Factor (HIF) Prolyl Hydroxylases. Acs Chem Biol 8, 1488-1496.

Cruz-Molina, S., Respuela, P., Tebartz, C., Kolovos, P., Nikolic, M., Fueyo, R., ljcken, W.F.J. van, Grosveld, F., Frommolt, P., Bazzi, H., et al. (2017). PRC2 Facilitates the Regulatory Topology Required for Poised Enhancer Function during Pluripotent Stem Cell Differentiation. Cell Stem Cell 20, 689-705.e9.

Dennis, G., Sherman, B.T., Hosack, D.A., Yang, J., Gao, W., Lane, H.C., and Lempicki, R.A. (2003). DAVID: Database for Annotation, Visualization, and Integrated Discovery. Genome Biol 4, R60.

Dumoulin, J.C.M., Meijers, C.J.J., Bras, M., Coonen, E., Geraedts, J.P.M., and Evers, J.L.H. (1999). Effect of oxygen concentration on human in-vitro fertilization and embryo culture*. Hum Reprod 14, 465-469.

Evans, M.J., and Kaufman, M.H. (1981). Establishment in culture of pluripotential cells from mouse embryos. Nature 292, 154-156.

Fan, R., Kim, Y.S., Wu, J., Chen, R., Zeuschner, D., Mildner, K., Adachi, K., Wu, G., Galatidou, S., Li, J., et al. (2020). Wnt/Beta-catenin/Esrrb signalling controls the tissue-scale reorganization and maintenance of the pluripotent lineage during murine embryonic diapause. Nat Commun 11, 5499.

Feldmann, A., Ivanek, R., Murr, R., Gaidatzis, D., Burger, L., and Schübeler, D. (2013). Transcription Factor Occupancy Can Mediate Active Turnover of DNA Methylation at Regulatory Regions. Plos Genet 9, e1003994.

Fischer, B., and Bavister, B.D. (1993). Oxygen tension in the oviduct and uterus of rhesus monkeys, hamsters and rabbits. Reproduction 99, 673-679.

Forristal, C.E., Wright, K.L., Hanley, N.A., Oreffo, R.O.C., and Houghton, F.D. (2010). Hypoxia inducible factors regulate pluripotency and proliferation in human embryonic stem cells cultured at reduced oxygen tensions. Reproduction Camb Engl 139, 85-97.

Frias-Aldeguer, J., Kip, M., Vivié, J., Li, L., Alemany, A., Korving, J., Darmis, F., Oudenaarden, A. van, Geijsen, N., and Rivron, N.C. (2020). Embryonic signals perpetuate polar-like trophoblast stem cells and pattern the blastocyst axis. Biorxiv 510362. 
George, S.H.L., Gertsenstein, M., Vintersten, K., KoretsSmith, E., Murphy, J., Stevens, M.E., Haigh, J.J., and Nagy, A. (2007). Developmental and adult phenotyping directly from mutant embryonic stem cells. Proceedings of the National Academy of Sciences of the United States of America 104, 4455-4460.

Girgin, M.U., Broguiere, N., Mattolini, L., and Lutolf, M.P. (2021). Gastruloids generated without exogenous Wnt activation develop anterior neural tissues. Stem Cell Rep 16, 1143-1155.

Goedhart, J. (2020). PlotTwist: A web app for plotting and annotating continuous data. Plos Biol 18, e3000581.

Grosswendt, S., Kretzmer, H., Smith, Z.D., Kumar, A.S., Hetzel, S., Wittler, L., Klages, S., Timmermann, B., Mukherji, S., and Meissner, A. (2020). Epigenetic regulator function through mouse gastrulation. Nature 584, 102-108.

Harvey, A.J., Kind, K.L., Pantaleon, M., Armstrong, D.T., and Thompson, J.G. (2004). Oxygen-Regulated Gene Expression in Bovine Blastocysts. Biol Reprod 71, 11081119.

Hayashi, K., Ohta, H., Kurimoto, K., Aramaki, S., and Saitou, M. (2011). Reconstitution of the Mouse Germ Cell Specification Pathway in Culture by Pluripotent Stem Cells. Cell 146, 519-532.

Houghton, F.D. (2021). HYPOXIA AND REPRODUCTIVE HEALTH: Hypoxic regulation of preimplantation embryos: lessons from human embryonic stem cells. Reproduction 161, F41-F51.

Hu, Q., Qin, Y., Ji, S., Xu, W., Liu, W., Sun, Q., Zhang, Z., Liu, M., Ni, Q., Yu, X., et al. (2019). UHRF1 promotes aerobic glycolysis and proliferation via suppression of SIRT4 in pancreatic cancer. Cancer Lett 452, 226-236.

Hu, Z., Tan, D.E.K., Chia, G., Tan, H., Leong, H.F., Chen, B.J., Lau, M.S., Tan, K.Y.S., Bi, X., Yang, D., et al. (2020). Maternal factor NELFA drives a $2 \mathrm{C}$-like state in mouse embryonic stem cells. Nat Cell Biol 22, 175-186.

Kent, W.J., Zweig, A.S., Barber, G., Hinrichs, A.S., and Karolchik, D. (2010). BigWig and BigBed: enabling browsing of large distributed datasets. Bioinformatics 26, 2204-2207.

Kim, J.-H., Shim, J.-W., Eum, D.-Y., Kim, S.D., Choi, S.H., Yang, K., Heo, K., and Park, M.-T. (2017). Downregulation of UHRF1 increases tumor malignancy by activating the CXCR4/AKT-JNK/IL-6/Snail signaling axis in hepatocellular carcinoma cells. Sci Rep-Uk 7, 2798.

Kinoshita, M., Barber, M., Mansfield, W., Cui, Y., Spindlow, D., Stirparo, G.G., Dietmann, S., Nichols, J., and Smith, A. (2021). Capture of Mouse and Human Stem Cells with Features of Formative Pluripotency. Cell Stem Cell 28, 453-471.e8.

Koch, F., Scholze, M., Wittler, L., Schifferl, D., Sudheer, S., Grote, P., Timmermann, B., Macura, K., and Herrmann, B.G. (2017). Antagonistic Activities of Sox2 and Brachyury Control the Fate Choice of NeuroMesodermal Progenitors. Dev Cell 42, 514-526.e7.

Kojima, Y., Kaufman-Francis, K., Studdert, J.B., Steiner, K.A., Power, M.D., Loebel, D.A.F., Jones, V., Hor, A., de Alencastro, G., Logan, G.J., et al. (2014). The
Transcriptional and Functional Properties of Mouse Epiblast Stem Cells Resemble the Anterior Primitive Streak. Cell Stem Cell 14, 107-120.

Koumenis, C., Naczki, C., Koritzinsky, M., Rastani, S., Diehl, A., Sonenberg, N., Koromilas, A., and Wouters, B.G. (2002). Regulation of Protein Synthesis by Hypoxia via Activation of the Endoplasmic Reticulum Kinase PERK and Phosphorylation of the Translation Initiation Factor elF2a. Mol Cell Biol 22, 7405-7416.

Kozak, K.R., Abbott, B., and Hankinson, O. (1997). ARNT-Deficient Mice and Placental Differentiation. Dev Biol 191, 297-305.

Kulak, N.A., Pichler, G., Paron, I., Nagaraj, N., and Mann, M. (2014). Minimal, encapsulated proteomic-sample processing applied to copy-number estimation in eukaryotic cells. Nat Methods 11, 319-324.

Kunath, T., Arnaud, D., Uy, G.D., Okamoto, I., Chureau, C., Yamanaka, Y., Heard, E., Gardner, R.L., Avner, P., and Rossant, J. (2005). Imprinted X-inactivation in extraembryonic endoderm cell lines from mouse blastocysts. Development 132, 1649-1661.

Kusuma, S., Peijnenburg, E., Patel, P., and Gerecht, S. (2014). Low Oxygen Tension Enhances Endothelial Fate of Human Pluripotent Stem Cells. Arteriosclerosis Thrombosis Vasc Biology 34, 913-920.

Lee, P., Chandel, N.S., and Simon, M.C. (2020). Cellular adaptation to hypoxia through hypoxia inducible factors and beyond. Nature Reviews. Molecular Cell Biology 21, 268-283.

Lie, D.-C., Colamarino, S.A., Song, H.-J., Désiré, L., Mira, H., Consiglio, A., Lein, E.S., Jessberger, S., Lansford, H., Dearie, A.R., et al. (2005). Wnt signalling regulates adult hippocampal neurogenesis. Nature 437, 1370-1375.

Lolas, M., Valenzuela, P.D.T., Tjian, R., and Liu, Z. (2014). Charting Brachyury-mediated developmental pathways during early mouse embryogenesis. Proc National Acad Sci 111, 4478-4483.

Manzo, G. (2019). Similarities Between Embryo Development and Cancer Process Suggest New Strategies for Research and Therapy of Tumors: A New Point of View. Frontiers Cell Dev Biology 7, 20.

Martens, L., Hermjakob, H., Jones, P., Adamski, M., Taylor, C., States, D., Gevaert, K., Vandekerckhove, J., and Apweiler, R. (2005). PRIDE: The proteomics identifications database. Proteomics 5, 3537-3545.

Martin, G.R. (1981). Isolation of a pluripotent cell line from early mouse embryos cultured in medium conditioned by teratocarcinoma stem cells. Proc National Acad Sci 78, 7634-7638.

Martin, M. (2011). Cutadapt removes adapter sequences from high-throughput sequencing reads. Embnet $\mathrm{J} 17$, 10-12.

Mazumdar, J., O’Brien, W.T., Johnson, R.S., LaManna, J.C., Chavez, J.C., Klein, P.S., and Simon, M.C. (2010). $\mathrm{O} 2$ regulates stem cells through $\mathrm{Wnt} / \beta$-catenin signalling. Nat Cell Biol 12, 1007-1013.

Meintjes, M., Chantilis, S.J., Douglas, J.D., Rodriguez, A.J., Guerami, A.R., Bookout, D.M., Barnett, B.D., and Madden, J.D. (2009). A controlled randomized trial 
evaluating the effect of lowered incubator oxygen tension on live births in a predominantly blastocyst transfer program. Hum Reprod 24, 300-307.

Meuter, A., Rogmann, L.-M., Winterhoff, B.J., Tchkonia, T., Kirkland, J.L., and Morbeck, D.E. (2014). Markers of cellular senescence are elevated in murine blastocysts cultured in vitro: molecular consequences of culture in atmospheric oxygen. J Assist Reprod Gen 31, 12591267.

Mittnenzweig, M., Mayshar, Y., Cheng, S., Ben-Yair, R., Hadas, R., Rais, Y., Chomsky, E., Reines, N., Uzonyi, A., Lumerman, L., et al. (2021). A single-embryo, single-cell time-resolved model for mouse gastrulation. Cell 184, 2825-2842.e22.

Mohyeldin, A., Garzón-Muvdi, T., and Quiñones-Hinojosa, A. (2010). Oxygen in Stem Cell Biology: A Critical Component of the Stem Cell Niche. Cell Stem Cell 7, 150-161.

Montfoort, A.P.A.V., Arts, E.G.J.M., Wijnandts, L., Sluijmer, A., Pelinck, M.-J., Land, J.A., and EchtenArends, J.V. (2020). Reduced oxygen concentration during human IVF culture improves embryo utilization and cumulative pregnancy rates per cycle. Hum Reproduction Open 2020, hoz036.

Mori, H., Yao, Y., Learman, B.S., Kurozumi, K., Ishida, J., Ramakrishnan, S.K., Overmyer, K.A., Xue, X., Cawthorn, W.P., Reid, M.A., et al. (2016). Induction of WNT11 by hypoxia and hypoxia-inducible factor- $1 \alpha$ regulates cell proliferation, migration and invasion. Sci Rep-Uk 6, 21520.

Moris, N., Anlas, K., Brink, S.C. van den, Alemany, A., Schröder, J., Ghimire, S., Balayo, T., Oudenaarden, A. van, and Arias, A.M. (2020). An in vitro model of early anteroposterior organization during human development. Nature 582, 410-415.

Murray, J.K., Balan, C., Allgeier, A.M., Kasparian, A., Viswanadhan, V., Wilde, C., Allen, J.R., Yoder, S.C., Biddlecome, G., Hungate, R.W., et al. (2010). DipeptidylQuinolone Derivatives Inhibit Hypoxia Inducible Factor-1a Prolyl Hydroxylases-1, -2 , and -3 with Altered Selectivity. J Comb Chem 12, 676-686.

Muz, B., Puente, P. de la, Azab, F., and Azab, A.K. (2015). The role of hypoxia in cancer progression, angiogenesis, metastasis, and resistance to therapy. Adv Exp Med Biol Volume 3, 83-92.

Neagu, A., Genderen, E. van, Escudero, I., Verwegen, L., Kurek, D., Lehmann, J., Stel, J., Dirks, R.A.M., Mierlo, G. van, Maas, A., et al. (2020). In vitro capture and characterization of embryonic rosette-stage pluripotency between naive and primed states. Nat Cell Biol 22, 534545.

Nguyen, A.Q., Bardua, I., Greene, B., Wrenzycki, C., Wagner, U., and Ziller, V. (2020). Mouse embryos exposed to oxygen concentrations that mimic changes in the oviduct and uterus show improvement in blastocyst rate, blastocyst size, and accelerated cell division. Reprod Biology 20, 147-153.

Ni, Y., Hagras, M.A., Konstantopoulou, V., Mayr, J.A., Stuchebrukhov, A.A., and Meierhofer, D. (2019). Mutations in NDUFS1 Cause Metabolic Reprogramming and Disruption of the Electron Transfer. Cells 8, 1149.
Olmsted, Z.T., and Paluh, J.L. (2021). Co-development of central and peripheral neurons with trunk mesendoderm in human elongating multi-lineage organized gastruloids. Nat Commun 12, 3020.

Ottosen, L.D., Hindkjær, J., Husth, M., Petersen, D.E., Kirk, J., and Ingerslev, H.J. (2006). Observations on intrauterine oxygen tension measured by fibre-optic microsensors. Reprod Biomed Online 13, 380-385.

Pagé, E.L., Robitaille, G.A., Pouysségur, J., and Richard, D.E. (2002). Induction of Hypoxia-inducible Factor-1a by Transcriptional and Translational Mechanisms*. J Biol Chem 277, 48403-48409.

Pettersen, E.O., Juul, N.O., and Rønning, O.W. (1986). Regulation of protein metabolism of human cells during and after acute hypoxia. Cancer Res 46, 4346-4351.

Pimton, P., Lecht, S., Stabler, C.T., Johannes, G., Schulman, E.S., and Lelkes, P.I. (2015). Hypoxia Enhances Differentiation of Mouse Embryonic Stem Cells into Definitive Endoderm and Distal Lung Cells. Stem Cells Dev 24, 663-676.

Platt, J.L., Salama, R., Smythies, J., Choudhry, H., Davies, J.O., Hughes, J.R., Ratcliffe, P.J., and Mole, D.R. (2016). Capture-C reveals preformed chromatin interactions between HIF-binding sites and distant promoters. Embo Rep 17, 1410-1421.

Podkalicka, P., Stępniewski, J., Mucha, O., Kachamakova-Trojanowska, N., Dulak, J., and Łoboda, A. (2020). Hypoxia as a Driving Force of Pluripotent Stem Cell Reprogramming and Differentiation to Endothelial Cells. Biomol 10, 1614.

Rankin, E.B., and Giaccia, A.J. (2016). Hypoxic control of metastasis. Science 352, 175-180.

Ritchie, M.E., Phipson, B., Wu, D., Hu, Y., Law, C.W., Shi, W., and Smyth, G.K. (2015). limma powers differential expression analyses for RNA-sequencing and microarray studies. Nucleic Acids Res 43, e47-e47.

Rodriguez-Terrones, D., Hartleben, G., Gaume, X., Eid, A., Guthmann, M., Iturbide, A., and Torres-Padilla, M. (2020). A distinct metabolic state arises during the emergence of 2-cell-like cells. Embo Rep 21, e48354.

Rossant, J., Chazaud, C., and Yamanaka, Y. (2003). Lineage allocation and asymmetries in the early mouse embryo. Philosophical Transactions Royal Soc Lond Ser B Biological Sci 358, 1341-1349.

Schwab, L.P., Peacock, D.L., Majumdar, D., Ingels, J.F., Jensen, L.C., Smith, K.D., Cushing, R.C., and Seagroves, T.N. (2012). Hypoxia-inducible factor $1 \alpha$ promotes primary tumor growth and tumor-initiating cell activity in breast cancer. Breast Cancer Res 14, R6.

Shao, M., Hepler, C., Zhang, Q., Shan, B., Vishvanath, L., Henry, G.H., Zhao, S., An, Y.A., Wu, Y., Strand, D.W., et al. (2021). Pathologic HIF1a signaling drives adipose progenitor dysfunction in obesity. Cell Stem Cell 28, 685-701.e7.

Sharif, J., Muto, M., Takebayashi, S., Suetake, I., Iwamatsu, A., Endo, T.A., Shinga, J., Mizutani-Koseki, Y., Toyoda, T., Okamura, K., et al. (2007). The SRA protein Np95 mediates epigenetic inheritance by recruiting Dnmt1 to methylated DNA. Nature 450, 908-912. 
Sozen, B., Cox, A.L., Jonghe, J.D., Bao, M., Hollfelder, F., Glover, D.M., and Zernicka-Goetz, M. (2019). SelfOrganization of Mouse Stem Cells into an Extended Potential Blastoid. Dev Cell 51, 698-712.e8.

Sozen, B., Jorgensen, V., Zhu, M., Cui, T., and ZernickaGoetz, M. (2021). Reconstructing human early embryogenesis in vitro with pluripotent stem cells. Biorxiv 2021.03.12.435175.

Stadler, M.B., Murr, R., Burger, L., Ivanek, R., Lienert, F., Schöler, A., Nimwegen, E. van, Wirbelauer, C., Oakeley, E.J., Gaidatzis, D., et al. (2011). DNA-binding factors shape the mouse methylome at distal regulatory regions. Nature 480, 490-495.

Tanaka, S., Kunath, T., Hadjantonakis, A.-K., Nagy, A., and Rossant, J. (1998). Promotion of Trophoblast Stem Cell Proliferation by FGF4. Science 282, 2072-2075.

Tsakiridis, A., Huang, Y., Blin, G., Skylaki, S., Wymeersch, F., Osorno, R., Economou, C., Karagianni, E., Zhao, S., Lowell, S., et al. (2014). Distinct Wnt-driven primitive streak-like populations reflect in vivo lineage precursors. Development 141, 1209-1221.

Turner, D.A., Girgin, M., Alonso-Crisostomo, L., Trivedi, V., Baillie-Johnson, P., Glodowski, C.R., Hayward, P.C., Collignon, J., Gustavsen, C., Serup, P., et al. (2017). Anteroposterior polarity and elongation in the absence of extra-embryonic tissues and of spatially localised signalling in gastruloids: mammalian embryonic organoids. Development 144, 3894-3906.

Tzouanacou, E., Wegener, A., Wymeersch, F.J., Wilson, V., and Nicolas, J.-F. (2009). Redefining the Progression of Lineage Segregations during Mammalian Embryogenesis by Clonal Analysis. Dev Cell 17, 365376.

Veenvliet, J.V., and Herrmann, B.G. (2021). Modeling mammalian trunk development in a dish. Dev Biol 474, 515.
Veenvliet, J.V., Bolondi, A., Kretzmer, H., Haut, L., Scholze-Wittler, M., Schifferl, D., Koch, F., Guignard, L., Kumar, A.S., Pustet, M., et al. (2020). Mouse embryonic stem cells self-organize into trunk-like structures with neural tube and somites. Science 370 , eaba4937.

Vianello, S., and Lutolf, M.P. (2020). In vitro endoderm emergence and self-organisation in the absence of extraembryonic tissues and embryonic architecture. Biorxiv 2020.06.07.138883.

Wickham, H. (2016). ggplot2, Elegant Graphics for Data Analysis. R 109-145.

Woods, L., Perez-Garcia, V., and Hemberger, M. (2018). Regulation of Placental Development and Its Impact on Fetal Growth-New Insights From Mouse Models. Front Endocrinol 9, 570.

Xu, P.-F., Borges, R.M., Fillatre, J., Oliveira-Melo, M. de, Cheng, T., Thisse, B., and Thisse, C. (2021). Construction of a mammalian embryo model from stem cells organized by a morphogen signalling centre. Nat Commun 12, 3277.

Yedwab, G.A., Paz, G., Homonnai, T.Z., David, M.P., and Kraicer, P.F. (1976). The Temperature, $\mathrm{pH}$, and Partial Pressure of Oxygen in the Cervix and Uterus of Women and Uterus of Rats During the Cycle. Fertil Steril 27, 304309.

Ying, Q.-L., Wray, J., Nichols, J., Batlle-Morera, L., Doble, B., Woodgett, J., Cohen, P., and Smith, A. (2008). The ground state of embryonic stem cell self-renewal. Nature 453, 519-523.

Zhang, X., Peterson, K.A., Liu, X.S., McMahon, A.P., and Ohba, S. (2013). Gene Regulatory Networks Mediating Canonical Wnt Signal-Directed Control of Pluripotency and Differentiation in Embryo Stem Cells. Stem Cells 31, 2667-2679. 


\section{METHODS}

\section{Cell lines and culture conditions}

Wild-type E14 mouse ES cells (Sarah Kinkley Lab) were cultured without feeders on gelatincoated plates $(0.1 \%$ gelatin, Sigma-Aldrich G1393). The media was changed every day and cells were passaged every 2 days. At each passage, cells were dissociated using TrypLE (Thermo Fisher 12604-021) and replated at appropriate density. Cells were maintained at $37^{\circ} \mathrm{C}$ in a humidified $5 \% \mathrm{CO}_{2}$ incubator. TS cells (Magdalena Zernicka-Goetz Lab) were cultured on feeders using TS cell culture media. Cells were passaged in a 1:10 to $1: 20$ ratio every 4 to 6 days. XEN cells (from Zernicka-Goetz Lab) were cultured on gelatincoated plates using XEN cell culture media. Cells were passaged in 1:20 or 1:40 ratio every 2 to 3 days. Cells in normoxia were cultured with $20 \% \quad \mathrm{O}_{2}$ while cells in hypoxia were cultured with $2 \% \quad \mathrm{O}_{2}$ unless otherwise specified.

\section{Media and supplements}

ES cell culture media: DMEM/High glucose with Glutamax media (Thermo, 31966047) supplemented with $15 \%$ FBS (Thermo, 2206648RP), 1x non-essential amino acids, 1x Penicillin/streptomycin, 1x $\beta$-mercaptoethanol, $1000 U / \mathrm{mL}$ LIF.

TS cell culture media: RPMI 1640 (Gibco, 61870010) supplemented with 1x Glutamax, $20 \%$ FBS, $1 \mathrm{mM}$ sodium pyruvate (Thermo, 11360070), 1.3x $\beta$-mercaptoethanol, 1x Penicillin/streptomycin, 25ng/ml FGF4 (R\&D systems, 235-F4-025) and $1 \mu \mathrm{g} / \mathrm{ml}$ Heparin (Sigma, H3149).

XEN cell culture media: DMEM + GlutaMAX (Gibco, 10566016) supplemented with 15\% FBS, $1 \mathrm{x}$ non-essential amino acids, 1x Penicillin/streptomycin, 1x $\beta$-mercaptoethanol, $1 \mathrm{mM}$ Sodium pyruvate, 20mM HEPES (Sigma, H0887). Media was conditioned on mouse embryonic fibroblasts for 3 days and filtered before use. Then, feeder-conditioned media was mixed in a 7:3 ratio with unconditioned XEN media.

\section{Inhibitor treatments}

For activation of Hif $1 \alpha$, cells were cultured in normoxia and treated with 50 or $100 \mu \mathrm{M}$ IOX2
(Sigma, SML0652) dissolved in DMSO (Sigma, D2650)

For DNA demethylation experiments, cells were cultured in normoxia and treated with $1 \mu \mathrm{M}$ Dnmt1 inhibitor (MedChem Tronica, HY-135146) dissolved in DMSO.

For inhibition of oxidative phosphorylation, cells were cultured in normoxia and treated with $1 \mu \mathrm{M}$ Carbonyl cyanide 4(trifluoromethoxy)phenylhydrazone (FCCP) (Sigma, C2920) dissolved in DMSO.

For glycolysis inhibition, cells were cultured in hypoxia and treated with $50 \mu \mathrm{M}$ 3bromopyruvate (3-BP) (Sigma, 376817) dissolved in DMSO.

\section{Growth curve}

Cells were grown at a density of $0.25,0.75$, and 0.5 million cells per $10 \mathrm{~cm}$ dish for ES, TS, and XEN cells, respectively in normoxia or hypoxia $2 \% \mathrm{O}_{2}$, and were counted every day.

\section{Apoptosis assay}

Cells were cultured in normoxia and hypoxia $2 \% \mathrm{O}_{2}$ for 7 days. Then, the CellEvent Caspase-3/7 Green Flow Cytometry Assay Kit (Thermo, C10740) was used. Briefly, cells were collected and incubated with 500nM CellEvent Caspase-3/7 at RT for 1 hour. During the last 5 minutes, $1 \mu \mathrm{M}$ Sytox was added. As negative controls, cells were incubated in the absence of both reagents (double negative control), only with Caspase 3/7 or only with Sytox (single negative controls). Cells were analyzed on FACS AriaFusion. Data were analyzed using FlowJo (version 10) and plotted using GraphPadPrism (version 8).

\section{Cell cycle analysis}

ES cells were cultured in normoxia and hypoxia $2 \% \mathrm{O}_{2}$ for 7 days. To study cell cycle distribution, the Click-iT EdU Alexa Fluor 488 Flow Cytometry Assay Kit (Thermo, C10425) was used. Briefly, on day 7 , cells were incubated at $37^{\circ} \mathrm{C}$ for 1 hour with $10 \mu \mathrm{M}$ EdU. Following the incubation, 1 million cells were collected and dislodged in fixative for at RT for 15 minutes. Then, cells were washed and mixed with the reaction cocktail (Alexa Fluor 488 azide) and incubated for 30 minutes. Cells were treated with 1:1000 DNA content stain FxCycle Violet in FACS media (PBS $+1 \%$ FBS). Cells were analyzed on FACS AriaFusion. Data were analyzed using FlowJo 
(version 10) and plotted using GraphPadPrism (version 8).

\section{RNA extraction and real-time qPCR}

Total RNA was extracted using the Qiagen RNeasy kit (Qiagen, 74004), following the manufacturer's instructions. $5 \mu \mathrm{g}$ of RNA was used as input to generate complementary DNA (cDNA) with the High-Capacity cDNA Reverse Transcription Kit (Thermo, 4368814) using random primers. As a control, a reaction without reverse transcriptase enzyme (-RT control) was performed. cDNA was diluted 1:5 and was used to perform real-time quantitative PCR (qPCR) using primers designed to amplify specific target genes (Table S10) using KAPA SYBR FAST qPCR Master Mix (2X) ABI Prism (Thermo, KK4617) on the QuantStudio 7 Flex Real-Time PCR System (Applied Biosystems) thermal cycler. As a control, a reaction without cDNA was performed.

\section{Western Blot}

Whole-cell extracts: Cell pellets were resuspended in RIPA buffer (Thermo, 89900) containing $1 \mathrm{x}$ protease inhibitor cocktail (Thermo, 78425), incubated at $4^{\circ} \mathrm{C}$ for 30 minutes, followed by centrifugation at maximum speed and $4^{\circ} \mathrm{C}$ for 20 minutes. Afterward, the supernatant was collected and the protein concentration was determined using Pierce ${ }^{\mathrm{TM}} \mathrm{BCA}^{\mathrm{TM}}$ Protein-Assay (Thermo, 23225). $10-20 \mu \mathrm{g}$ of protein was used for subsequent steps.

Subcellular fragmentation of cytoplasm and nucleus: Cell were washed with buffer $A$ (10mM HEPES pH7.9 (Gibco, 15630-080), $5 \mathrm{mM} \mathrm{MgCl} 2$ (Sigma, M8266), 0.25M Sucrose (Sigma, S7903), 0.1\% Igepal 630 (Merck, 56741), 1x protease inhibitor cocktail, $1 \mathrm{mM}$ PMSF, $1 \mathrm{mM} \mathrm{NaVO}$ and incubated on ice for 10 minutes. Afterward, samples were passed through $18 \mathrm{G}$ needles and centrifuged again for 10 minutes. Pellet corresponding to the nuclear fraction was resuspended in cold buffer $B$ (10mM HEPES pH7.9, $1 \mathrm{mM} \mathrm{MgCl}_{2}, 0.1 \mathrm{mM}$ EDTA (Jena Bioscience, BU-105), 25\% glycerol (Sigma, G5516), $0.5 \mathrm{M} \mathrm{NaCl}$ (Invitrogen, AM9760G) and 0.5\% Triton X-100 were added and incubated on ice for 30 minutes. Samples were passed through $18 \mathrm{G}$ needles and sonicated using Bioruptor with the settings 30 seconds on 30 seconds off for 5 minutes. Subcellular fractions were quantified using Pierce ${ }^{\mathrm{TM}} \mathrm{BCA}^{\mathrm{TM}}$ Protein-Assay. 10-20 $\mu \mathrm{g}$ protein was used for subsequent steps.

SDS-PAGE: Samples were mixed with $4 x$ ROTI loading buffer (Carlroth, K929.2), heated at $98^{\circ} \mathrm{C}$ for 5 minutes, and loaded on $4-15 \%$ Mini-PROTEAN®TGX ${ }^{\mathrm{TM}}$ precast protein gels (Biorad, 4561083). Proteins were separated by electrophoresis at $70 \mathrm{~V}$ for 15 minutes followed by $100 \mathrm{~V}$ for approximately 1 hour using 10x Tris/Glycine/SDS running buffer (BioRad, 1610772).

Blotting and detection: Proteins were transferred to a PVDF membrane (Thermo, IB24001) using the iBlot 2 dry blotting system (Thermo, IB21001) and run at 20V for 7 minutes. After blotting, membranes were blocked with $5 \%$ milk in TBS-T buffer (Thermo, 28360) for 1 hour at room temperature. For detection of the protein of interest, membranes were incubated at $4^{\circ} \mathrm{C}$ overnight with primary antibody (Table S10) in 5\% milk in TBS-T buffer, followed by secondary antibody at RT for 1 hour. For detection, membranes were incubated with ECL Western Blotting Substrate (Thermo, 32106) for 1 minute prior to imaging with the ChemiDoc system (BioRad).

\section{Immunofluorescence (IF)}

IF was either performed on colonies or seeded single cells. For imaging of colonies, cells were cultured on Falcon 8-well Culture Slides (Corning, 354108) coated with gelatin (XEN, ES) or uncoated (TS). For single-cell staining, 50.000 to 100.000 cells were seeded on Matrigel (Corning, 356230) for 30 minutes. Cells were washed with 1 XPBS before fixation using 4\% PFA (Sigma, P6148) for $10 \mathrm{~min}$ at RT. After fixation cells were washed with $1 \times P B S$ and permeabilized using $0.4 \%$ Triton$\mathrm{X} 100$ in PBS-T for $15 \mathrm{~min}$ at RT. After permeabilization, samples were washed in PBS-T and blocked in PBS-T + $2 \%$ BSA (NEB, $\mathrm{B} 9000)+5 \%$ donkey/goat serum (Jackson Immunoresearch/Dianova, 017-000-121) for $1 \mathrm{~h}$ at RT. Cells were incubated with primary antibodies diluted 1:200 to 1:1000 in blocking buffer overnight at $4^{\circ} \mathrm{C}$. Samples were washed three times $10 \mathrm{~min}$ at RT in PBS-T + 2\% BSA and subsequently incubated with secondary antibodies diluted 1:1000 in blocking buffer for $1 \mathrm{~h}$ at RT. Samples were washed three times for $10 \mathrm{~min}$ at RT in PBS-T + 2\% BSA. Cells were mounted in Vectashield (H1200) with DAPI (Biozol, VEC-H-2000-10). Imaging was performed with confocal laser scanning 
microscope LSM800 (Zeiss). Fluorescence intensities were quantified using CellProfiler (https://cellprofiler.org/) (Carpenter et al., 2006). Intensities were normalized to the nuclear area and plotted in $\mathrm{R}$ using ggplot2 (Wickham, 2016).

\section{RNA-sequencing}

Sample collection: Total RNA was extracted using the Qiagen RNeasy kit and quantified using Qubit 3.0. Two biological replicates were collected per condition.

Library preparation and sequencing: Library preparation was performed using KAPA RNA HyperPrep Kit (Kapa Biosystems, KR1350) (input amount 500ng RNA, adapter concentration $1.5 \mu \mathrm{M}$ and PCR cycle number = 10)), and samples were sequenced using Illumina HiSeq4000, in 75-bp, paired-end format.

Mapping and analysis: Raw reads were subjected to adapter and quality trimming with cutadapt (version 2.4; parameters: --nextseqtrim 20 --overlap 5 --minimum-length 25 -a d a p ter AGATCGGAAGAGC - A AGATCGGAAGAGC), followed by poly-A trimming with cutadapt (parameters: --overlap 20 --minimum-length 25 --adapter "A[100]" -adapter "T[100]"). Reads were aligned to the mouse reference genome (mm10) using STAR (version 2.7.5a; parameters: --runMode alignReads --chimSegmentMin 20 -outSAMstrandField intronMotif --quantMode GeneCounts) and transcripts were assembled using StringTie (version 2.0.6; parameters: -e) with GENCODE annotation (VM19). Table of read counts was generated using featureCounts function of the Rsubread package (version 1.32.4). To filter lowly expressed genes, count-per-million (CPM) was calculated using EdgeR package (version 3.26.8). Genes having > 0.4 CPM in at least 2 out of 6 samples were kept. Additionally, only coding protein genes were used for further analysis. Transcripts Per Kilobase Million (TPM) was used to generate normalized expression values. Differentially expressed genes (DEG) were determined using EdgeR package, applying multiple-testing adjusted $P$ (FDR) $<=0.1$ significance threshold and absolute fold-change $>1.5$. Complete lists of DE genes are available in Table S1.

Principal component analysis was performed with the built-in $R$ functions prcomp and hierarchical clustering was made with dendextend library (version 1.14.0) using dist function to compute distance between sample and hclust to perform hierarchical clustering. PCA and volcano plots were generated using ggplot2 (version 3.3.0). Heatmaps were generated using GraphPadPrism (version 8).

Selection of germ layers and lineage markers. Marker genes from different cell states were selected following the single-cell transcriptional reference profile of early post-implantation development from (Grosswendt et al., 2020). Early ecto-, endo- and mesoderm germ layers represents marker genes that were reliably assigned to cell states within these three lineage cell fates from E6.5 to E7.5.

For later cell states, lineage specific marker genes from node \& notochord (E7.0-8.0, mesoderm lineage), neuromesodermal (E7.5-8.0, mesoderm lineage), paraxial \& posterior mesoderm (E7.5-8.5, mesoderm lineage), primitive gut (E7.5-8.5, endoderm lineage) and for mid brain \& spinal cord (E7.5-8.5, ectoderm lineage) were selected.

Gene ontology-biological process (GO-BP) analysis: GO-BP analyses were performed using DAVID web-tools (Dennis et al., 2003). Selected terms were plotted in dot plot format using ggplot2. Complete lists of GO terms are available in Table S2.

Analysis of $\mathrm{T}$ target genes: $\mathrm{T}$ ChIP-seq and RNA-seq data were retrieved from (Lolas et al., 2014). Briefly, T-activated (FC>2) or Trepressed genes (FC<-2) in in vitro primitive streak differentiated cells on day 4 vs. ES cells were selected. Expression levels of these $T$ target genes in hypoxia day 2 , day 7 and normoxia was plotted in heatmap format using pheatmap package (version 1.0.12) showing row z-score normalized expression values. Annotation bars were added to show which of these genes are differentially expressed in hypoxia day 2 and/or day 7 compared to normoxia.

\section{Global proteomics}

Sample preparation: Proteomics sample preparation was done according to a published protocol with minor modifications (Kulak et al., 2014). In brief, 5 million cells in biological duplicates of 2 days and 7 days hypoxia treatment and normoxia controls were lysed under denaturing conditions in $500 \mu \mathrm{l}$ of a buffer containing $3 \mathrm{M}$ guanidinium chloride ( Gdm Cl), $\quad 10 \quad \mathrm{~m} \mathrm{M} \quad t r i s(2-$ carboxyethyl)phosphine, $40 \mathrm{mM}$ 
chloroacetamide, and $100 \mathrm{mM}$ Tris- $\mathrm{HCl} \mathrm{pH}$ 8.5. Lysates were denatured at $95^{\circ} \mathrm{C}$ for $10 \mathrm{~min}$ shaking at $1000 \mathrm{rpm}$ in a thermal shaker and sonicated in a water bath for $10 \mathrm{~min}$. $100 \mu \mathrm{l}$ lysate was diluted with a dilution buffer containing $10 \%$ acetonitrile and $25 \mathrm{mM}$ Tris$\mathrm{HCl}, \mathrm{pH} 8.0$, to reach a $1 \mathrm{M} \mathrm{GdmCl}$ concentration. Then, proteins were digested with LysC (Roche, Basel, Switzerland; enzyme to protein ratio $1: 50$, MS-grade) shaking at 700 $\mathrm{rpm}$ at $37^{\circ} \mathrm{C}$ for 2 hours. The digestion mixture was diluted again with the same dilution buffer to reach $0.5 \mathrm{M} \mathrm{GdmCl}$, followed by tryptic digestion (Roche, enzyme to protein ratio 1:50, MS-grade) and incubation at $37^{\circ} \mathrm{C}$ overnight in a thermal shaker at $700 \mathrm{rpm}$. Peptide desalting was performed according to the manufacturer's instructions (Pierce C18 Tips, Thermo Scientific, Waltham, MA). Desalted peptides were reconstituted in $0.1 \%$ formic acid in water and further separated into four fractions by strong cation exchange chromatography (SCX, 3M Purification, Meriden, CT). Eluates were first dried in a SpeedVac, then dissolved in 5\% acetonitrile and $2 \%$ formic acid in water, briefly vortexed, and sonicated in a water bath for 30 seconds prior injection to nano-LC-MS/MS.

Run parameters: LC-MS/MS was carried out by nanoflow reverse-phase liquid chromatography (Dionex Ultimate 3000, Thermo Scientific) coupled online to a QExactive HF Orbitrap mass spectrometer (Thermo Scientific), as reported previously (Ni et al., 2019). Briefly, the LC separation was performed using a PicoFrit analytical column (75 $\mu \mathrm{m}$ ID $\times 50 \mathrm{~cm}$ long, $15 \mu \mathrm{m}$ Tip ID; New Objectives, Woburn, MA) in-house packed with 3- $\mu \mathrm{m}$ C18 resin (Reprosil-AQ Pur, Dr. Maisch, Ammerbuch, Germany).

Peptide analysis: Raw MS data were processed with MaxQuant software (v1.6.10.43) and searched against the mouse proteome database UniProtKB with 55,153 entries, released in August 2019. The MaxQuant processed output files can be found in Table S8, showing peptide and protein identification, accession numbers, \% sequence coverage of the protein, q-values, and labelfree quantification (LFQ) intensities. The mass spectrometry data have been deposited to the ProteomeXchange Consortium (http:// proteomecentral.proteomexchange.org) via the PRIDE partner repository (Martens et al., 2005) with the dataset identifier PXD026641.
Complete proteome profiles are available in Table S3.

Differential expression analysis: The DEP package (version 1.6.1) was used. First, duplicate proteins, contaminants, and proteins that were not found in at least 2 out of the total number of samples $(n=6)$ were filtered. A total number of 4,260 proteins were identified. The LFQ values were normalized using the background correction variance stabilizing transformation (VSN). Missing values were imputed using a left-censored imputation method as the proteins with missing values were biased to low expression values. Differential expression analysis was run with test_diff function from DEP package which uses limma (Ritchie et al., 2015). Differentially expressed proteins (DEP) were defined applying multiple-testing adjusted $P$ (Benjamini-Hochberg) $<0.05$ significant threshold and fold-change with an absolute value of $>1.5$. Complete lists of DEP are available in Table S4.

Scatter plots show mean LFQ values in hypoxia vs normoxia and were generated using ggplot2. GO-BP analysis was performed using DAVID web tools (Dennis et al., 2003).

\section{Simultaneous determination of cytidine modifications by targeted LC-MS/MS}

Sample preparation: Genomic DNA was extracted using the PureLink Genomic DNA Mini Kit following the manufacturer's instructions. $300 \mathrm{ng}$ genomic DNA were used for profiling the following cytidine modifications in E14 mouse ES cells samples: 2'deoxycytidine (dC), 5-methyl-2'-deoxycytidine (5-mdC), 5-hydroxymethyl-2'-deoxycytidine (5hmdC), 5-formyl-2'-deoxycytidine (5-fodC), and 5-carboxyl-2'-deoxycytidine (5-cadC), as well as the other three bases 2'-deoxyguanosine $(\mathrm{dG}), 2^{\prime}$-deoxyadenosine (dA), thymidine ( $\left.\mathrm{T}\right)$. A multiple reaction monitoring (MRM) method with three transitions was established by using pure compounds. Furthermore, a dilution series of these standards was used for absolute quantification. 300 ng DNA was dissolved in a total of $21.5 \mu \mathrm{L}$ water in Protein LoBind Tubes, $2.5 \mu \mathrm{L}$ DNA Degradase buffer, and $1 \mu \mathrm{L}$ DNA Degradase Plus enzyme (Zymo Research, Freiburg, Germany) were added. The DNA digestion efficiency was monitored by using $100 \mathrm{ng}$ 5-methylcytosine and 5hydroxymethylcytosine DNA standard sets (Zymo Research) in parallel under identical 
conditions. The digest was carried out at $37^{\circ} \mathrm{C}$ on a rocking platform (600 rpm) for 2 hours. 1 $\mu \mathrm{L}$ of $100 \mu \mathrm{M}$ chloramphenicol was added as an internal standard as well as $1 \mu \mathrm{L}$ of $5 \%$ formic acid to inactivate the digest.

Run parameters: $180 \mathrm{ng}$ of the DNA digests were used for LC-MS/MS analysis. Cytidine separation was performed on an LC instrument (1290 series UHPLC; Agilent, Santa Clara, CA), online coupled to a triple quadrupole hybrid ion trap mass spectrometer QTrap 6500 (Sciex, Foster City, CA). Cytidines were eluted from a Reprosil-PUR C18-AQ $(1.9 \mu \mathrm{m}, 120 \AA$, $150 \times 2 \mathrm{~mm}$ ID; Dr. Maisch; Ammerbuch, Germany) column at a controlled temperature of $30{ }^{\circ} \mathrm{C}$, using a gradient from 2 to $98 \%$ solvent $B$ in solvent $A$ over 10 min at $250 \mu \mathrm{L}$ per minute flow rate. Solvent $A$ was $10 \mathrm{mM}$ ammonium acetate, pH 3.5 (adjusted with acetic acid) and solvent $B$ was $0.1 \%$ formic acid in acetonitrile. Transition settings are provided in Table S9, consisting of three transitions for each base. Transitions were monitored in a 240-second window of the expected elution time and acquired at unit resolution (peak width at $50 \%$ was $0.7 \pm 0.1 \mathrm{Da}$ tolerance) in quadrupole Q1 and Q3. Data acquisition was performed with an ion spray voltage of $5.5 \mathrm{kV}$ in positive mode of the ESI source, N2 as the collision gas was set to high, curtain gas was set to $30 \mathrm{psi}$, ion source gas 1 and 2 were set to 50 and 70 psi, respectively, and an interface heater temperature of $350^{\circ} \mathrm{C}$ was used.

Analysis: Relative quantification of the peaks was performed using MultiQuant software v.2.1.1 (Sciex, Foster City, CA). The integration settings were a peak-splitting factor of 5 and a Gaussian smoothing width of 2 All peaks were reviewed manually. Only the average peak area of the first transition was used for calculations. Normalization was done according to IS. All original LC-MS generated QTrap wiff files, as well as MultiQuant v.2.1.1 (Sciex, Foster City, CA). Results were plotted using GraphPad Prism.

\section{ChIP-sequencing}

Chromatin extracts were prepared as described in (Brookes et al., 2012). Briefly, cells were fixed with $1 \%$ formaldehyde (Thermo, 28906) in PBS at RT for 10 minutes. Then, 0.125M glycine (Sigma, 50046) was added to quench formaldehyde at RT for 5 minutes. Cells were washed twice with ice-cold
PBS. To lyse, fixed cells were treated with swelling buffer (25mM HEPES pH 7.9, 1.5mM $\mathrm{MgCl}_{2}, 10 \mathrm{mM} \mathrm{KCl}$ (Invitrogen, AM9640G), $0.1 \%$ Igepal $630,1 \times$ protease inhibitor cocktail, $1 \mathrm{mM}$ PMSF, $2 \mathrm{mM} \mathrm{NaVO} 3,5 \mathrm{mM} \mathrm{NaF}$ ) at $4^{\circ} \mathrm{C}$ for 10 minutes. Cells were scraped on ice and passed through $18 \mathrm{G}$ needles before centrifugation at $3000 \mathrm{~g}, 4^{\circ} \mathrm{C}$ for 5 minutes. Cell pellet, corresponding to nuclei was carefully resuspended in sonication buffer $(50 \mathrm{mM}$ HEPES pH 7.9, $140 \mathrm{mM} \mathrm{NaCl}, 1 \mathrm{mM}$ EDTA, $1 \%$ Triton X-100, 0.1\% Sodium-deoxycholade (Thermo, 89904), $0.1 \%$ SDS (Invitrogen, AM9822), 1mM PMSF, $2 \mathrm{mM} \mathrm{NaVO} 3,5 \mathrm{mM}$ $\mathrm{NaF}$ ) and incubated on ice for 10 minutes before sonication. Chromatin was sheared to an average size of 200-300bp with E220 Evolution Covaris sonicator for 6 cycles, 1 minute each. Shearing efficiency was checked by agarose gel.

$10 \mu \mathrm{g}$ chromatin was incubated with $5 \mu \mathrm{L}$ of HIF1 $\alpha$ antibody (concentration not provided) (CST, 36169, lot:2), $20 \mu \mathrm{L}$ of Protein A/G dynabeads (Thermo, 10002D/10004D) in sonication buffer overnight. Beads were washed twice with sonication buffer, followed by a wash with high salt buffer (sonication buffer with $500 \mathrm{mM} \mathrm{NaCl}$ instead) and TE buffer (10mM Tris- $\mathrm{HCl} \mathrm{pH}$ 8.5, (Teknova, T5085), $1 \mathrm{mM}$ EDTA, $1 \%$ SDS). Then, the sample was resuspended in elution buffer $(50 \mathrm{mM}$ Tris- $\mathrm{HCl}$ pH 7.5 (Sigma, T2319), 1mM EDTA, 1\% SDS). Samples were treated with RNase A (Thermo, EN0531) at $37^{\circ} \mathrm{C}$ for 30 minutes, followed by Proteinase $\mathrm{K}$ (NEB, P8107S) at $65^{\circ} \mathrm{C}$ overnight. Genomic DNA was purified using MinElute PCR purification kit (Qiagen, 28004) and quantified by Qubit 3.0. Two biological replicates were collected per condition.

Library preparation and sequencing: Libraries were prepared using the KAPA Hyper Prep Kit (Kapa Biosystems, KR0961) (input amount 10ng DNA, adapter concentration $1.5 \mu \mathrm{M}$, and size selection of 200-700-bp after PCR with cycle number $=15)$. Samples were sequenced using NovaSeq 6000, in 100-bp, paired-end format.

Mapping and analysis: Raw reads of treatment and input samples were subjected to adapter and quality trimming with cutadapt (Martin, 2011) (version 2.4; parameters: --nextseq-trim 20 --overlap 5 --minimum-length 25 --adapter AGATCGGAAGAGC -A AGATCGGAAGAGC). 
Reads were aligned to the mouse genome (mm10) using BWA with the 'mem' command (version 0.7.17, default parameters). A sorted BAM file was obtained and indexed using samtools with the 'sort' and 'index' commands (version 1.10). Duplicate reads were identified and removed using GATK (version 4.1.4.1) with the 'MarkDuplicates' command and default parameters. Peaks were called with reads aligning to the mouse genome only using MACS2 'callpeak' (version 2.1.2; parameters -bdg --SPMR) using the input samples as control samples. For downstream analyses, after validation of reproducibility, replicates were pooled using samtools 'merge'. Genomewide coverage tracks (signal files) for merged replicates normalized by library size were computed using samtools bamCoverage (version 3.4.3) (parameters: --normalizeUsing CPM --extendReads) When required, bedgraph files were also generated using bigWigToBedGraph from Kent utils tools (Kent et al., 2010). For identification of consistent HIF1 $\alpha$ peaks, only those that were identified in both replicates were used for downstream analyses. Peaks were annotated using ChIPseeker package (version 1.20.0) using default parameters (TSS region $\pm 3-K b$ ) and subdivided into peaks at promoter or distal regions. Complete list of HIF $1 \alpha$ peaks is available in Table S5.

Density plots were generated using computeMatrix (reference-point -referencePoint center) and plotHeatmap functions from Deeptools. Enrichment of different features was at $\pm 5-\mathrm{Kb}$ of centered HIF1 $\alpha$ peaks at promoters or distal regions. H3K27ac, p300, H3K4me3 and H3K4me1 ChIP-seq data generated on E14 ES cells were retrieved from (Cruz-Molina et al., 2017). Genome view of selected loci were generated using Spark (version 2.6.2). $\beta$-catenin ChIPseq data generated on V6.5 ES cells was retrieved from (Zhang et al., 2013) and analyzed following our ChIP-seq workflow.

Overlap of Hif1 $\alpha-, \beta$-catenin- and ES enhancer peaks was generated using intersect function (-wa -wb) from Bedtools (version 2.29.2). Venn diagram was generated manually.

Density plots were generated using computeMatrix (reference-point -referencePoint) for TSS and (scale-regions) for gene body resolution and plotHeatmap functions from Deeptools. Enrichment of different features was defined at 1) $\pm 2.5-\mathrm{Kb}$ of DE genes at promoters identified by RNA-seq.

\section{WGBS}

Sample preparation: Genomic DNA was extracted from 1 million cells using the PureLink Genomic DNA Mini Kit (Thermo, K182002) following manufacturer's instructions. gDNA was sheared in Covaris micro TUBE AFA Fiber Pre-Slit Snap-Cap tubes (SKU, 520045) and purified with the Zymo DNA Clean \& Concentrator-5 kit (D4013) according to manufacturer's instructions. The purified DNA was then bisulfite converted using the EZ DNA Methylation-Gold Kit (Zymo, D5005).

Library preparation and sequencing: WGBS libraries were processed using the Accel-NGS Methyl-seq DNA library kit (Swift Biosciences, DL-ILMMS-12) following manufacturer's recommendations. Libraries were prepared and cleaned using Agencourt AMPure XP beads (Beckman Coulter, A63881). The absence of adapters from the final libraries was verified using the Agilent TapeStation. The WGBS libraries were sequenced on the NovaSeq6000, in 150-bp, paired-end format.

Mapping and analysis: Raw reads were subjected to adapter and quality trimming with cutadapt (version 2.4; parameters: --qualitycutoff 20 --overlap 5 --minimum-length 25; Illumina TruSeq adapter clipped from both reads) followed by trimming of 10 nucleotides from the 5' and '3' end of both reads. The trimmed reads were aligned to the mouse genome (mm10) using BSMAP (version 2.90; parameters: -v 0.1 -s 16 -q 20 -w 100 -S 1 -u $-R)$. Duplicates were removed using the 'MarkDuplicates' command from GATK (version 4.1.4.1; --validation_stringency $=$ lenient --remove_duplicates=true). Methylation rates were called using mcall from the MOABS package (version 1.3.2; default parameters). Only CpGs covered by at least 10 and at most 150 reads located on autosomes or chromosome $\mathrm{X}$ were considered for all downstream analysis. Replicates were merged by calculating the average for each $\mathrm{CpG}$ covered by at least one of the two samples.

Genomic feature annotations: Genomic tiles were defined by segmenting the genome into regions of one $\mathrm{kb}$ size. The annotation of CGls was downloaded from UCSC for the mouse reference genome mm10. CGI shores were defined as the two kb regions flanking each 
CGI on either side. CGI shelves were defined as the two kb flanking the outer sides of CGI shores. Annotation of repeat elements was downloaded from RepeatMasker. The gene annotation was downloaded from GENCODE (VM19) and promoters were defined as the regions $1.5 \mathrm{~kb}$ upstream and $500 \mathrm{bp}$ downstream of the TSS.

Feature-wise DNA methylation: Average methylation levels per feature were calculated using the arithmetic mean based on the CpGs commonly covered by all samples (merged replicates). Only features with at least three covered CpGs were considered. For methylation differences per feature, the arithmetic mean of one sample was subtracted by the arithmetic mean of another sample.

Heatmaps of average promoter methylation were prepared using the 'pheatmap' $R$ package. Promoters were classified as overlapping with a $\mathrm{CGI}$ if at least $20 \%$ of the promoter or CGI were overlapping with each other.

DNA methylation levels at HIF1 $\alpha$ peaks: HIF1 $\alpha$ peaks at both promoter and distal regions were merged. $1-\mathrm{Kb}$ tiles signal files were used to quantify the mean methylation levels at HIF $1 \alpha$ peaks using map function (-c 4 - mean) from Deeptools. Mean methylation levels were used to generate violin plot using ggplot2.

\section{Gastruloid formation}

Male F1G4 mouse ES cells (George et al., 2007) were cultured on $6 \mathrm{~cm}$ plates (Corning 430166) gelatinized with $0.1 \%$ gelatin (Sigma G1393) and coated with mitotically inactive primary mouse embryo fibroblasts $\left(3-4 \times 10^{4}\right.$ cells $/ \mathrm{cm}^{2}$ ) with standard ES medium containing $15 \%$ FCS and $1000 \mathrm{U} / \mathrm{ml}$ leukemia inhibitory factor (LIF, Chemicon ESG1107) at $37^{\circ} \mathrm{C}$ and $5 \%$ CO2. ES cells were split every second day with a 1:10 dilution. For splitting, media was aspirated and cells were washed once with PBS and trypsinized (Trypsin-EDTA $(0.05 \%)$ (Gibco 25300054)) for $5-10$ minutes at $37^{\circ} \mathrm{C}$. Trypsin was neutralized by $3 \mathrm{ml}$ ES media and cells centrifuged for 5 minutes at $1000 \mathrm{rpm}$, after which the pellet was resuspended in ES media. ES cells were cultured in normoxia or hypoxia for 7 days. Gastruloids were then generated as described previously (Veenvliet et al., 2020) with some minor modifications. Briefly, ES cells were first depleted of feeders, then washed once in $5 \mathrm{ml}$ pre-heated $\left(37^{\circ} \mathrm{C}\right)$ PBS containing $\mathrm{MgCl} 2$ and $\mathrm{CaCl} 2$ (Sigma
D8662) and once in 5ml NDiff227 medium (Takara Y40002) pre-conditioned in normoxia or hypoxia. ES cells were then pelleted by centrifugation for 5 minutes at $1000 \mathrm{rpm}$ and resuspended in $250 \mu \mathrm{l}$ of NDiff227. $10 \mu \mathrm{l}$ of the cell suspension was mixed with $10 \mu$ l of Trypanblue (Bio-Rad 1450021) for automated cell counting with Luna Automated Cell Counter. 400 live cells were plated in a volume of $35 \mu \mathrm{l} \mathrm{NDiff227}$ into each well of a 96-well round bottom, low attachment plate (Costar 7007 ultra-low attachment 96 well plate (7007)). Cells were then allowed to aggregate for $48 \mathrm{~h}$ under normoxic or hypoxic conditions. After $48 \mathrm{~h}$, the aggregates were treated with $3 \mu \mathrm{M}$ CHIR99021 (CHIR, Merck Millipore) in $150 \mu \mathrm{l}$ NDiff227 for $24 \mathrm{~h}$ to induce robust gastruloid formation. For "-Chi" aggregates,

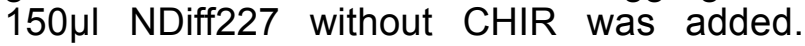
Between 72 and $120 \mathrm{~h}$, medium was refreshed every $24 \mathrm{~h}$ by removing $150 \mu \mathrm{l}$ of the old media and adding the same volume of new, preconditioned NDiff227.

Whole-mount immunofluorescence (WIFC) of gastruloids

Gastruloids were picked using a p200 pipette with the tip cut-off at the $50 \mu \mathrm{l}$ mark. Gastruloids were washed twice with PBS $+\mathrm{MgCl}_{2}$ and $\mathrm{CaCl}_{2}+0.5 \%$ BSA (Sigma A8412), once with PBS, and then fixed in 4\% PFA for 75 minutes in Ibidi 8-well glass-bottom plates (Ibidi 80827) at $4^{\circ} \mathrm{C}$ on a rocking platform. Subsequently, gastruloids were washed twice in PBS for 5 min, permeabilized by incubating for $3 \times 10$ minutes in $0.5 \%$ Triton-X/PBS (PBST), and blocked in $10 \%$ fetal calf serum/PBST (blocking solution) overnight at $4^{\circ} \mathrm{C}$. Primary antibody incubation was performed in blocking solution for $48-72 \mathrm{~h}$ at $4^{\circ} \mathrm{C}$, after which gastruloids were washed three times with blocking solution and three times with PBST. The following primary antibodies were used: rabbit anti-T (Cell Signaling, D2Z3J; 1:500), goat anti-SOX2 (R\&D Systems, AF2018; 1:500), goat anti-FOXA2 (Santa Cruz, sc-6554; 1:500). After the last washing step, gastruloids were incubated in blocking solution o/n at $4^{\circ} \mathrm{C}$. The next day, secondary antibodies diluted in blocking solution were added, and gastruloids were incubated for $24 \mathrm{~h}$ at $4^{\circ} \mathrm{C}$. The following secondary antibodies were used, all at a dilution of 1:500: donkey anti-rabbit Alexa Fluor 647 (Thermo, A31573), donkey anti-goat Alexa Fluor 546 (Thermo, A11056). Afterwards, 
gastruloids were washed three times with blocking solution and three times with PBST. The last PBST washing step after secondary antibody incubation included DAPI $(0.02 \%$, Roche Diagnostics 10236276001). DAPI was incubated for 5 hours or overnight and washed off once with PBS.

\section{Clearing and imaging of gastruloids}

Prior to imaging, gastruloids were embedded in agarose and cleared with RIMS (Refractive Index Matching Solution). To this end, 1.5\% low melting point (LMP), analytical grade (Promega, V2111) agarose was prepared in PBS, incubated at $80^{\circ} \mathrm{C}$ for 15 minutes, and cooled down to $37^{\circ} \mathrm{C}$ for 3 minutes in a thermomixer. Samples were washed twice with PBS for 10 minutes, post-fixed in 4\% PFA for 20 minutes, and washed three times with $0.1 \mathrm{M}$ phosphate buffer (PB, 0.025M Na $2 \mathrm{HPO}_{4}$, and $0.075 \mathrm{M} \mathrm{Na}_{2} \mathrm{HPO}_{4}, \mathrm{pH}$ 7.4). The pipette was set to $20 \mu \mathrm{l}$ and the gastruloids were stabilized on the IBIDI plate with a drop of LMP agarose for 5 minutes until the agarose was dry. The clearing was performed by incubation in $200 \mu l$ RIMS (133\% w/v Histodenz (Sigma, D2158) in $0.02 \mathrm{M}$ PB) on a rocking platform at $4^{\circ} \mathrm{C}$ for at least one to several days. Cleared gastruloids were imaged with the Zeiss LSM 880 Airyscan in confocal, Airyscan or Fastairy mode, using a Plan-Apochromat 20x/ NA=0.8 Objective, lateral pixel size of $0.1 .2-1.2 \mu \mathrm{m}$ and a typical z-spacing ranging from 1.9-3.3 $\mu \mathrm{m}$ and appropriate laser/filters for DAPI, Alexa Fluor 546, and Alexa Fluor 633 or combinations thereof. Bright-field images of non-cleared gastruloids were acquired with the Zeiss Celldiscoverer 7 , with a Plan-Apochromat $5 \times /$ $\mathrm{NA}=0.3$ Objective and a $1 \mathrm{x}$ postmagnification, lateral pixel size of $0.9 \mu \mathrm{m}$ and a typical zspacing of $10 \mu \mathrm{m}$, running under ZEN blue v3.1.

\section{Post-acquisition image processing and analysis}

Images captured in airy mode were processed under ZEN black 2.3 on a dedicated workstation. Confocal and wide-field image sets were downstream analyzed and further processed using a ZEN blue workstation (version 3.2). Maximum intensity projections (MIP) for gastruloids morphometrics analysis were achieved using customized macros in the open application development module in ZEN blue v3.2. Morphometric analysis was performed by either variance-based thresholding (bright-field images) or within confocal MIPs primary using Otsu intensity thresholds after faint gaussian smoothing, close by objects were segmented downstream by standard shedding.

Single cells image analysis of confocal datasets were also performed with customized analysis pipelines written in the image analysis module in ZEN blue. Briefly individual cells were identified by nuclear counterstainings after gaussian smoothing and background subtraction, adjusted to actual resolution of individual datasets, close by objects were segmented by water shedding. All objects/ nuclei were filtered after identification by area of 100-1000 $\mu^{2}$ and circularity of 0.6-1 (sqrt (4 $\times$ area $/ \pi \times$ FeretMax $\left.^{2}\right)$ ). Within the resulting regions of interest (cells) fluorescence signals of the counterstaining as well as T/FOXA2/ SOX2 were quantified. In total, > 10 million single objects were analyzed, plotted and further quantified using customized R-scripts.

Quantification of $\mathrm{T}$ expression across the anterior-posterior axis

$\mathrm{T}$ expression along the anterior-posterior axis was performed in ZEN 3.3 lite. In detail, Maximum intensity projections (MIP) previously developed by ZEN blue v3.2. were loaded into ZEN 3.3 lite. Brightness/contrast were automatically adjusted and a line (stroke thickness: 1) was manually drawn from the anterior to the posterior end of the structure along the midline, and the fluorescent intensity was measured using the "Profile" function on the software. The distance was measured in $\mathrm{nm}$.

To obtained binned intensities, first relative positions were calculated by dividing the absolute position by the total length of the structure, resulting in standardized relative positions on a 0-1 scale. Average intensities were then calculated for 0.01 sized bins, resulting in average intensity for 100 bins over the anterior-posterior axis. Plotting and kmeans clustering was performed using PlotTwist (Goedhart, 2020). 
bioRxiv preprint doi: https://doi.org/10.1101/2021.07.21.452906; this version posted July 22, 2021. The copyright holder for this preprint (which was not certified by peer review) is the author/funder. All rights reserved. No reuse allowed without permission.

A

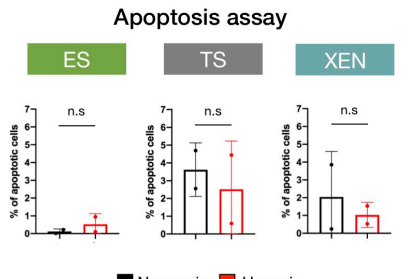

B

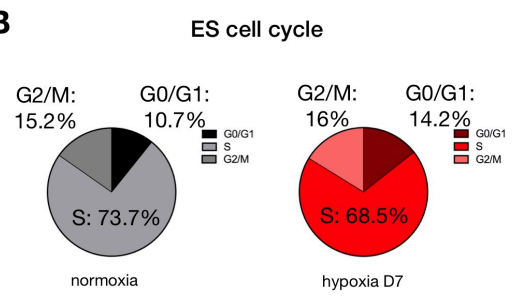

$\mathbf{F}$

GO-BP terms of DEGs in hypoxic TS

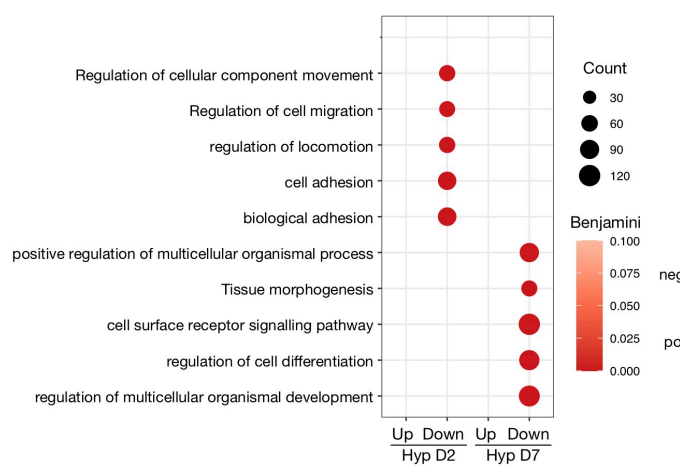

B

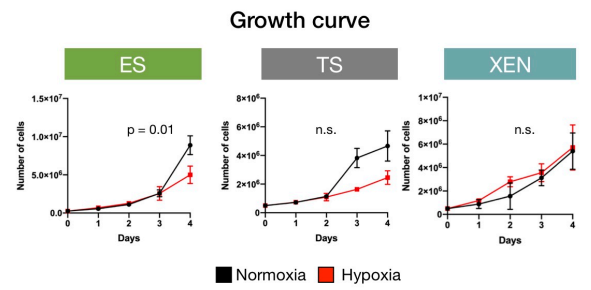

D

PCA

E Hierarchical clustering

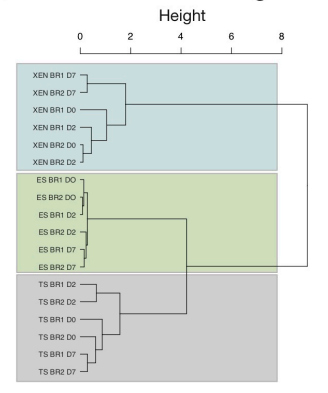

G

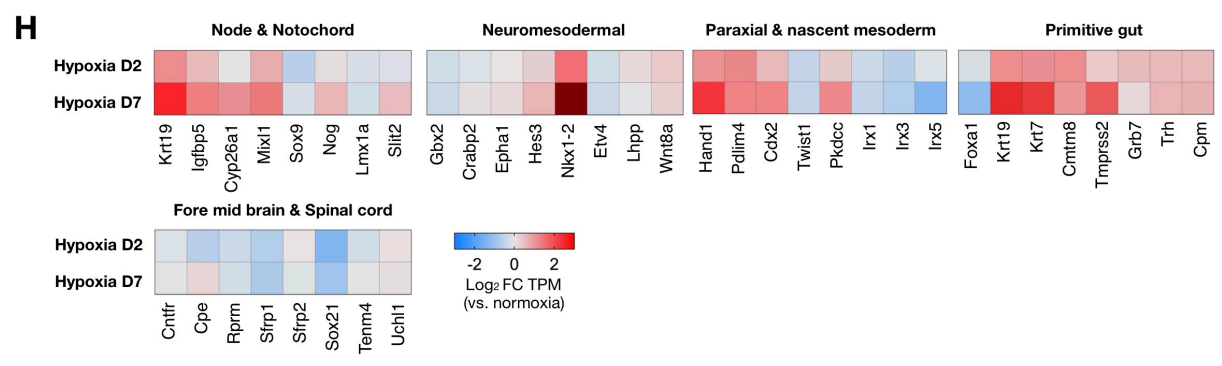

GO-BP terms of DEGs in hypoxic XEN

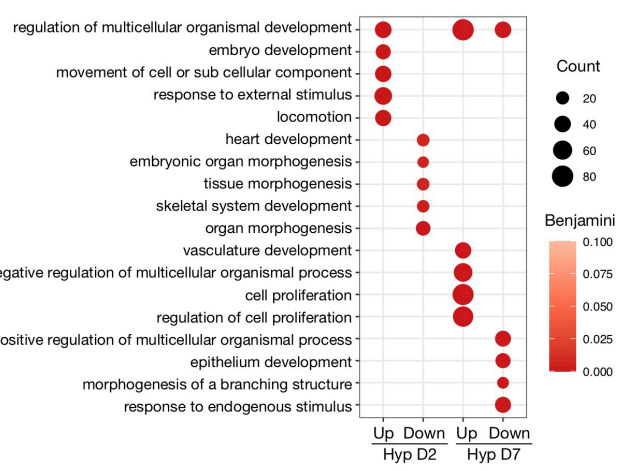

Figure S1. Further characterization of the hypoxic response in ES, TS, and XEN cells.

A) Apoptosis levels of normoxic or hypoxic (d7) ES, TS, and XEN cells. Apoptotic cells were defined as Casp3/7+/Sytox- See methods for more details. Two biological replicates were performed. The statistical test performed is a two-tailed paired Student's t-test.

B) Growth curves of ES, TS, and XEN cells grow in normoxia or hypoxia for 4 days. The same number of cells were seeded in both conditions and cells were counted daily. Two biological replicates were performed. The statistical test performed is a two-tailed paired Student's t-test.

C) Analysis of cell cycle phase distribution of normoxic or hypoxic (d7) ES cells. EdU and FxCycle Violet (DNA stain) were used.

D, E) Principal component analysis (PCA) (d) and hierarchical clustering (e) based on global transcriptomes of ES, TS, and XEN cells in hypoxia day 2, hypoxia day 7 , and normoxia.

F, G) GO-BP terms associated with DE genes in TS (f) and XEN (g) cells exposed to acute (d2) or prolonged (d7) hypoxia. Representative significant terms are shown (Benjamini-Hochberg adjusted $p$-value $<0.1$ ). No significant terms were retrieved for upregulated genes in TS cells on day 2 of hypoxia. See Table S2 for full list of GO terms.

$\mathrm{H}) \quad$ Heatmaps showing expression levels of the indicated genes in hypoxic relative to normoxic ES cells. Germ layer markers were retrieved by analyzing RNAseq data of gastrulating mouse embryos published in (Grosswendt et al., 2020) as explained in Methods (see 'Selection of germ layers and lineage markers' section). TPM, transcripts per million. FC, fold change. 
bioRxiv preprint doi: https://doi.org/10.1101/2021.07.21.452906; this version posted July 22, 2021. The copyright holder for this preprint (which was not certified by peer review) is the author/funder. All rights reserved. No reuse allowed without permission.

A

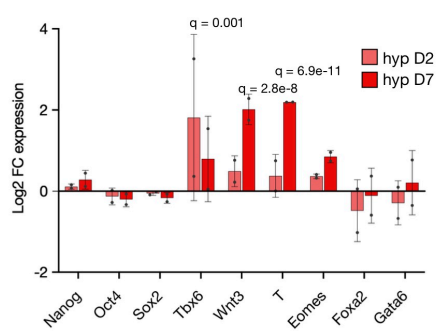

B

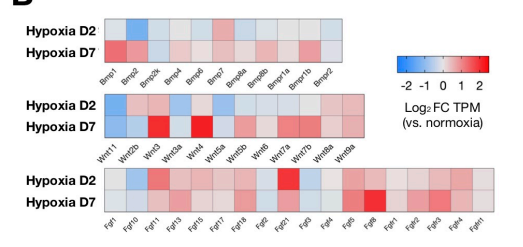

normoxia)

E

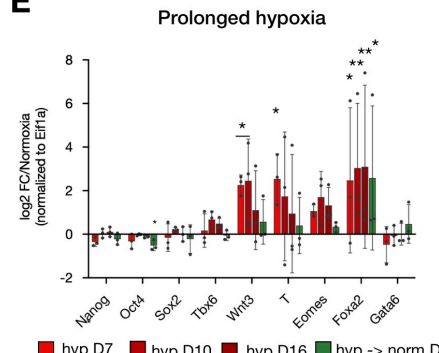

$\square$ hyp D7 $\square$ hyp D10 $\square$ hyp D16 $\square$ hyp -> norm D7

G

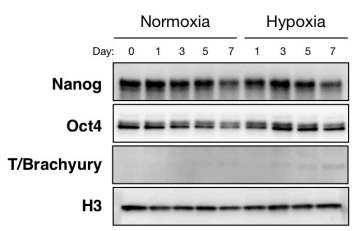

C $\quad$ ES (qPCR)

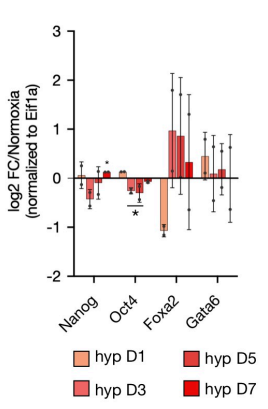

$\square$ hyp D3 $\square$ hyp D7

\section{2}
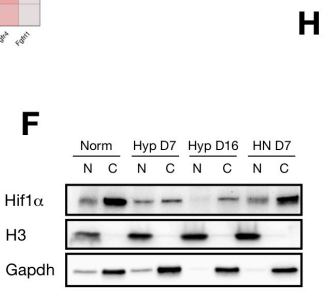

H

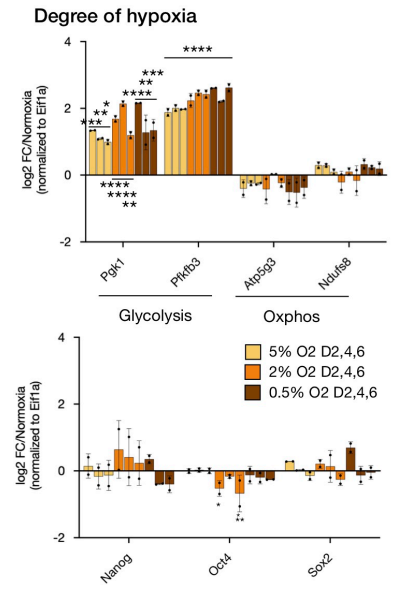

$T$ target genes expression

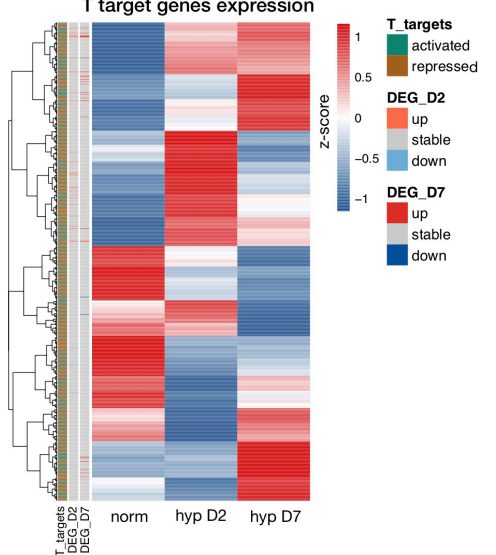

Figure S2. Further characterization of pluripotency and differentiation-associated gene activity in normoxic and hypoxic ES cells.

A) Relative expression levels of shown genes measured by RNA-seq. Data represent $\log _{2}$ FC over normoxic ES cells of TMP expression values and standard deviation.

B) Heatmaps showing expression levels of Bmp, Wnt, and Fgf, genes in hypoxic relative to normoxic ES cells.

C) Relative expression levels of shown genes in hypoxic ES cells measured by RT-qPCR. Data represent log ${ }_{2} F C$ over normoxia normalized to Eif1 $\alpha$ and standard deviation for two biological replicates. Other tested genes are available in Figure $2 \mathrm{~B}$. The statistical test performed is a two-tailed paired Student's t-test.

D) Relative expression levels of shown genes in ES cells exposed to different levels of hypoxia measured by RT-qPCR. Data represent log 2 FC over normoxia normalized to Eif1 $\alpha$ and standard deviation for two biological replicates. Other tested genes are available in Figure 2C.

E) Relative expression levels of shown genes in ES cells exposed to different durations of hypoxia (2\%) measured by RT-qPCR. Data represent log 2 FC over normoxia normalized to Eif1 $\alpha$ and standard deviation for three biological replicates.

F) Western blot showing expression levels and subcellular localization of Hif1 $\alpha$ in ES cells in normoxia or exposed to different durations of hypoxia. Gapdh and H3 were used as loading and fractionation controls. N, nuclear fraction. C, cytoplasmic fraction. HN D7, ES cells cultured in hypoxia for 7 days and then returned to normoxia for 7 days.

G) Western blot showing expression levels of the indicated genes in normoxic and hypoxic ES cells. H3 was used as a loading control.

$\mathrm{H}$ ) Heatmap showing expression levels of $\mathrm{T}$ target genes in normoxic and hypoxic ES cells. T target genes were identified as described in the Methods (see 'Analysis of T target genes' section) by analyzing data from (Lolas et al., 2014)). Bar annotations show, 1) T_targets; T -activated (in green) and -repressed (in brown) target genes in in vitro primitive streak differentiated cells, 2) DEG in hypoxia day 2 (D2) and day 7 (D7); up- (in red), down- (in blue) regulated and stable (in gray) genes on hypoxia day 2 and/or day 7.

Statistical tests performed are two-way ANOVA unless otherwise specified. $P$ value style: $p>0.05(n s), p<0.05\left({ }^{*}\right), p<0.01\left({ }^{* *}\right), p<0.001\left({ }^{* * *}\right)$, $p<0.0001\left(^{* * * *}\right)$. 
bioRxiv preprint doi: https://doi.org/10.1101/2021.07.21.452906; this version posted July 22, 2021. The copyright holder for this preprint (which was not certified by peer review) is the author/funder. All rights reserved. No reuse allowed without permission.
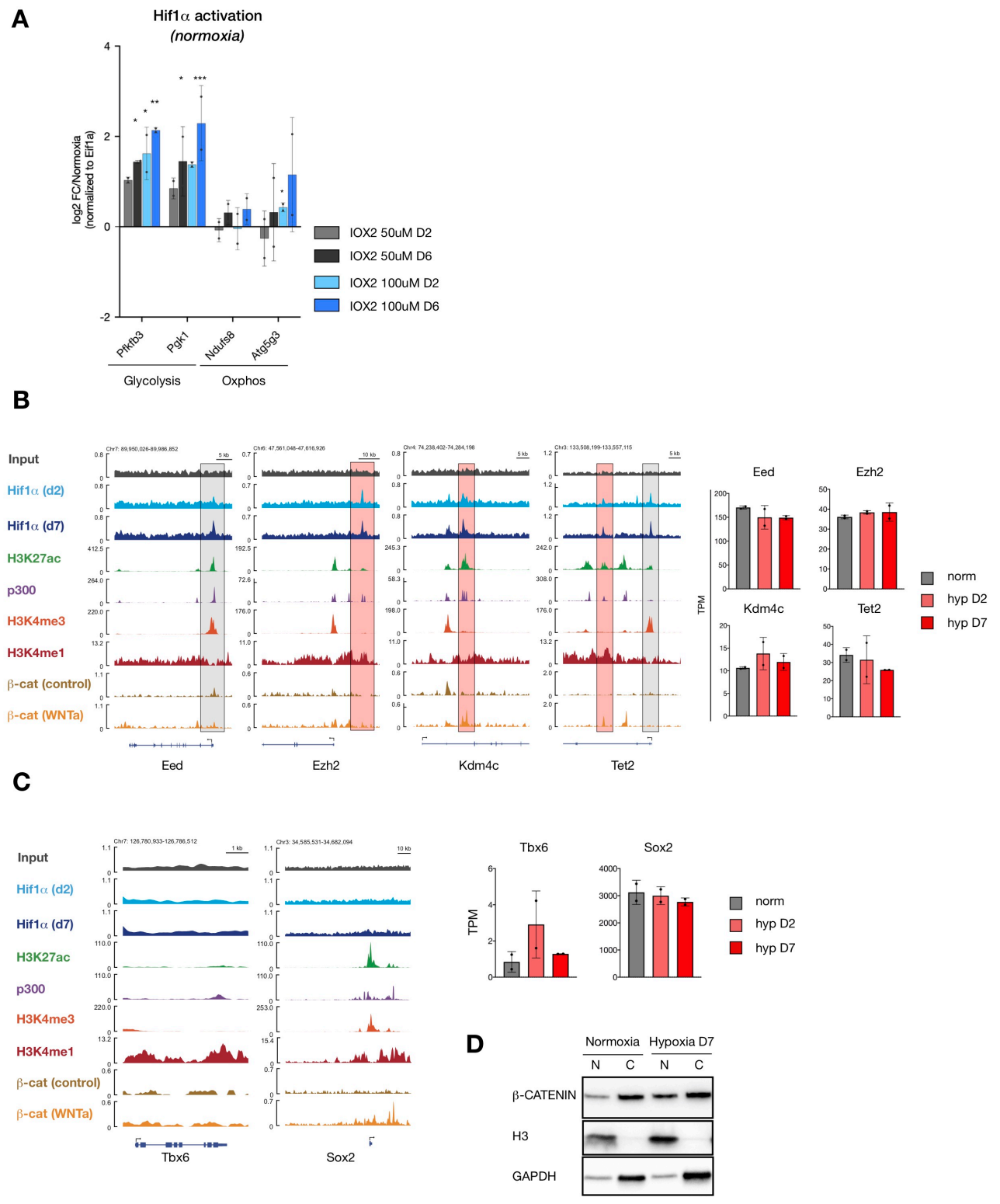

Figure S3. Further characterization of Hif1 $\alpha$ activity at chromatin in hypoxic ES cells.

A) Relative expression levels of shown genes in ES cells treated with the HIF1 $\alpha$ activator IOX2 at indicated concentrations in normoxia. Data represent $\log _{2} \mathrm{FC}$ over DMSO-treated ES cells normalized to Eif1 $\alpha$ and standard deviation for two biological replicates. Other tested genes are available in Figure 5A. Statistical test performed is a two-way ANOVA.

B, C) Genome browser views of chromatin occupancy and histone modifications at and epigenetic regulators (b) and lineage-specific genes (c). Expression values of the shown genes in normoxic and hypoxic ES cells as measured by RNA-seq are plotted as bar plots (right panels). Gray and red highlights indicate promoter and ES active enhancers respectively.

A) Western blot showing expression levels and subcellular localization of $\beta$-CATENIN in normoxic and hypoxic (d7) ES cells. Histone H3 is used as loading control. $\mathrm{H} 3$ and GAPDH were used as loading and fractionation controls. N, nuclear fraction. C, cytoplasmic fraction. 
bioRxiv preprint doi: https://doi.org/10.1101/2021.07.21.452906; this version posted July 22, 2021. The copyright holder for this preprint (which was not certified by peer review) is the author/funder. All rights reserved. No reuse allowed without permission.
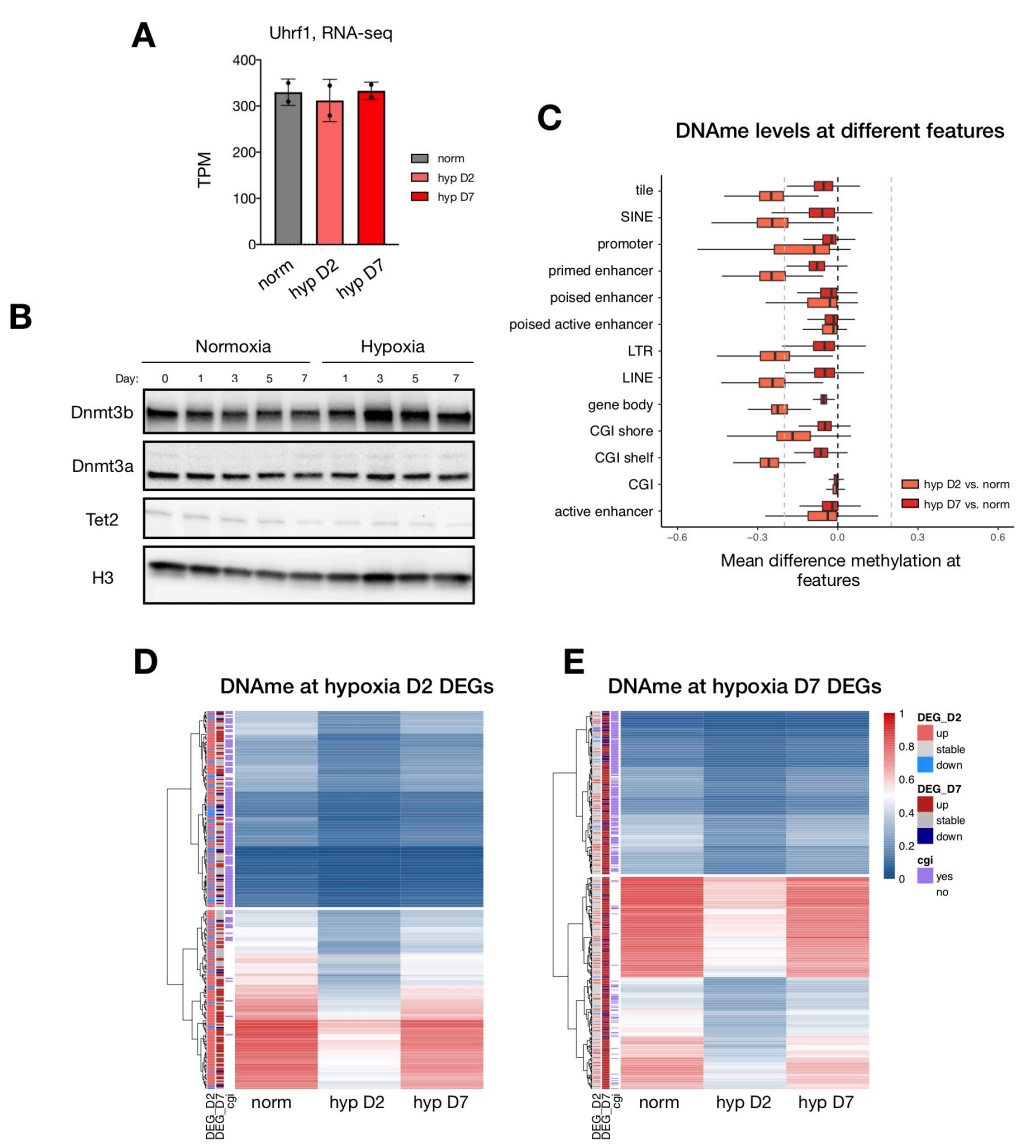

E

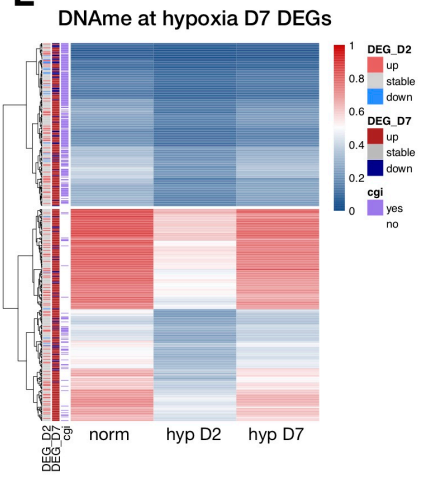

Figure S4. Characterization of DNA demethylation across the genome,

A) Expression levels of Uhrf1 in normoxic and hypoxic ES cells as measured by RNA-seq. TPM, transcripts per million.

B) Western blot showing expression levels of DNMT3b, DNMT3a, and TET2 in normoxic and hypoxic ES cells. H3 was used as loading control.

C) Box plot panel showing levels of DNA methylation reduction at different genomic features. Data represents mean difference methylation compared to normoxia of two biological replicates. Line indicates median and whiskers indicate variability outside the upper and lower quartiles.

D, E) Heatmaps showing mean DNA methylation levels of DE gene promoters identified in day 2 (c) or day 7 of hypoxia (d). Bar annotations (reported as DEG_D2 and DEG_D7) show the up- (in red), down- (in blue) regulated and stable (in gray) genes in hypoxia day 2 or day 7 . 
bioRxiv preprint doi: https://doi.org/10.1101/2021.07.21.452906; this version posted July 22, 2021. The copyright holder for this preprint (which was not certified by peer review) is the author/funder. All rights reserved. No reuse allowed without permission.

A
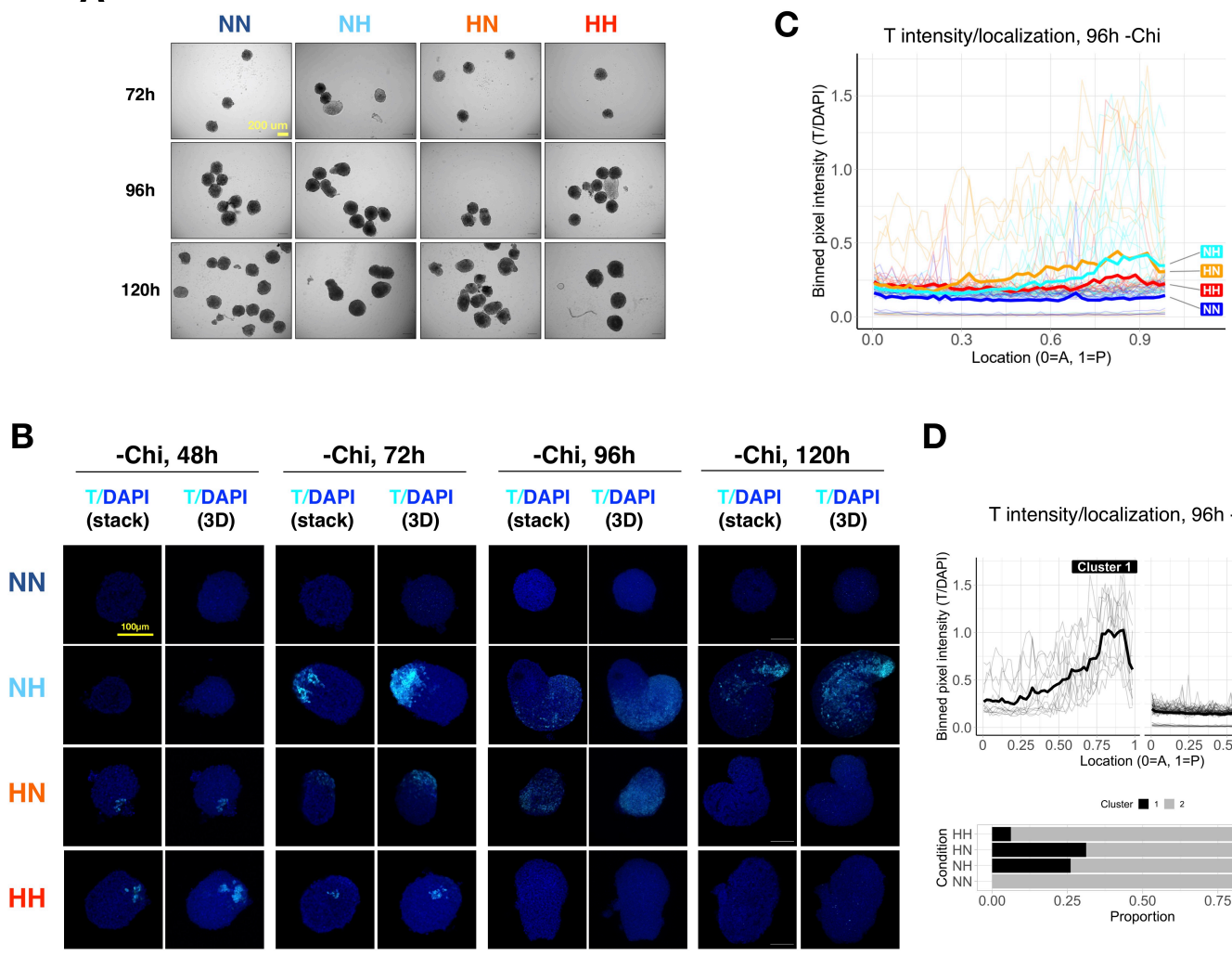

D
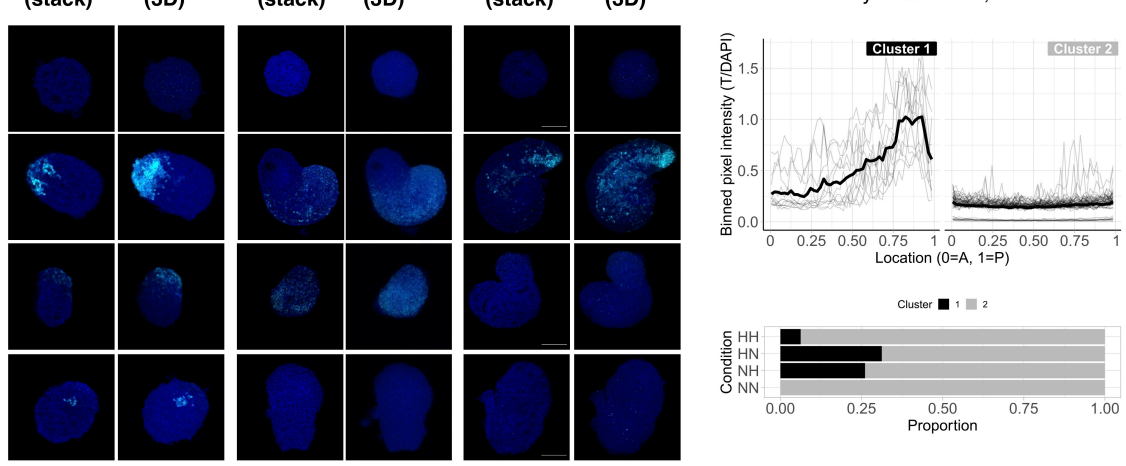

Figure S5. Hypoxia can induce spontaneous elongation of gastruloids in the absence of exogenous WNT activation.

A) Bright-field images of representative gastruloids at the indicated time points.

B) Confocal fluorescent microscopy images of representative -Chi gastruloids at indicated time points of culture. 3D, three-dimensional projection. Images were taken using the same settings for each time point, which may differ between time points.

C) Localization of T signal along the anterior-posterior (A-P) axis of gastruloids in each condition at 96h of culture. T signal normalized to DAPI and binned at $1 \%$ length increments along each structure for plotting. See Methods for details. Thick lines show mean values and thin lines show data from individual structures.

D) $\quad \mathrm{K}$-means clustering of the $\mathrm{NH}$ and $\mathrm{HN}$ structures presented in $\mathrm{C}$ ) with $\mathrm{n}=2$ clusters. 
bioRxiv preprint doi: https://doi.org/10.1101/2021.07.21.452906; this version posted July 22, 2021. The copyright holder for this preprint (which was not certified by peer review) is the author/funder. All rights reserved. No reuse allowed without permission.

A

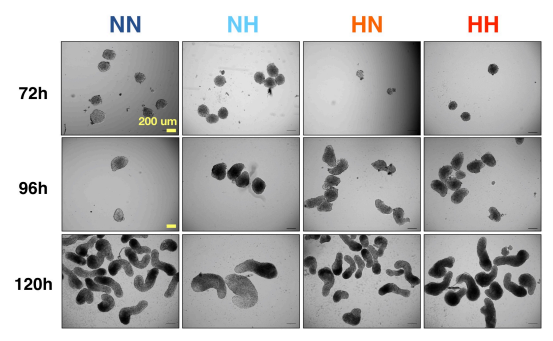

B
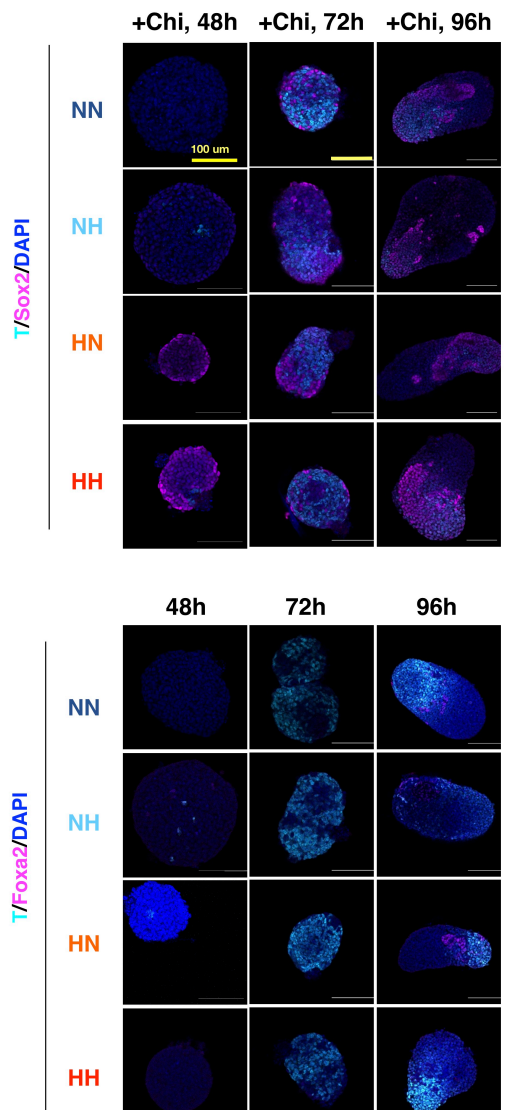

D

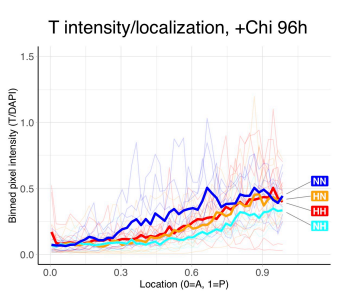

$\mathbf{E}$

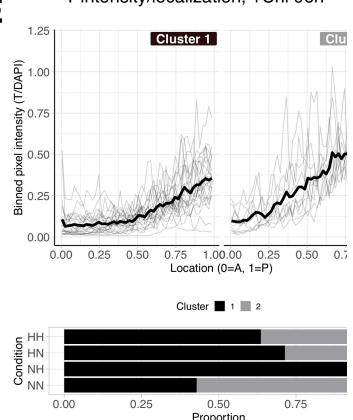

C
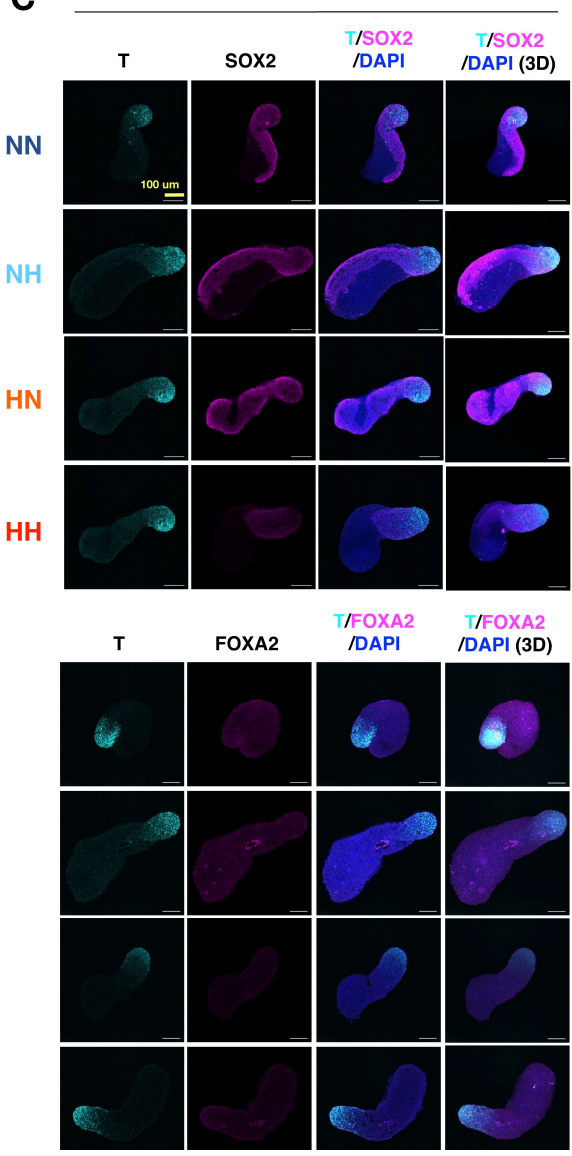

Figure S6. Further characterization of conventional gastruloids exposed to hypoxia.

A) Bright-field images of representative gastruloids at the indicated time points

B) Fluorescent microscopy images of representative gastruloids at early time points. Images show a single z-stack. For the same time point, images were taken using the same settings across conditions, but settings differ between time points.

C) Confocal fluorescent microscopy images of representative gastruloids at $120 \mathrm{~h}$ of culture. Images show a single z-stack, except those labeled 3D, which show 3D maximum intensity projections of the structure.

D) Localization of T signal along the anterior-posterior (A-P) axis of gastruloids in each condition. T signal was binned at $1 \%$ length increments along each structure for plotting and normalized to DAPI signal. Thick lines show the mean and thin lines show data from individual structures.

E) K-means clustering of all $96 \mathrm{~h}+$ Chi structures plotted in C) with $\mathrm{n}=2$ clusters. 
bioRxiv preprint doi: https://doi.org/10.1101/2021.07.21.452906; this version posted July 22, 2021. The copyright holder for this preprint (which was not certified by peer review) is the author/funder. All rights reserved. No reuse allowed without permission. 